\title{
LAS FUENTES DEL DERECHO LOCAL. PROBLEMAS GENERALES. COMPETENCIAS DEL ESTADO Y LAS COMUNIDADES AUTONOMAS
}

\author{
por
}

\author{
Luis Morell Ocaña
}

SUMARIO: I. LA PROBLEMATICA GENERAL DE LAS FUENTES DEL DERECHO LOCAL: 1. EL DUALISMO RATIO-AUCTORITAS EN LA TEORÍA DE LAS FUENTES DEL RÉGIMEN LOCAL. 2. FUENTES AUTÓNOMAS Y HETERÓNOMAS. 3. LA CONCURRENCIA DE PODERES NORMATIVOS: LA PLURALIDAD DE SITUACIONES DESDE EL PUNTO DE VISTA DE LA ORDENACIÓN DE LAS FUENTES. 4. DERECHO LOCAL Y DERECHO ADMINISTRATIVO COMÚN.-II. EL PLANTEAMIENTO ANALITICO DE LA LEGALIDAD: LA DISTINCION DE AMBITOS DE REGULACION Y LA PLURALIDAD DE TITULOS COMPETENCIALES EN CONTRASTE: 1. LA CONSIDERACIÓN DEL RÉGIMEN LOCAL DESDE LA PERSPECTIVA DE SUS FUENTES EN LA CONSTITUCIÓN Y EN LA LRBRL: A) El proceso interpretativo de los preceptos constitucionales: la clarificación de la competencia normativa del Estado: a) El artículo 149.1.18 de la Constitución como fundamento de la distribución: sus límites. $b$ ) El mínimo contenido habilitante del artículo 148.1.2. ${ }^{\circ}$ de la Constitución. B) Los criterios de la LRBRL: homogeneización de la competencia comunitaria y construcción plural del orden de prelación de fuentes. 2. AMBITOS SUSTANCIALES DE REGULACIÓN EN EL RÉGIMEN LOCAL.-III. EL ORDEN DE PRELACION DE FUENTES EN LOS DISTINTOS AMBITOS NORMATIVOS: 1. LAS ESTRUCTURAS LOCALES Y SUS ELEMENTOS. REGIMENES COMÚN, ESPECIAL Y FORAL: A) Contenido de este ámbito a efectos de distribución de las competencias normativas. B) Competencia estatal y comunitaria. 2. LA ORDENACIÓN DE LAS CORPORACIONES LOCALES COMO INSTITUCIONES REPRESENTATI- 
VAS. 3. El RÉGIMEN JURídico DE LAS ENTIDADES Locales EN CUANTO ADMINISTRACIONES PÚBLICAS: A) Contenido de este ámbito normativo. B) El planteamiento analítico de la LRBRL. 4. El PERSONAL AL SERVICIO DE LAS ENTIDADES LoCALES. 5. El RÉGIMEN DE LOS BIENES. 6. El RÉGIMEN DE LAS HaCIENDAS LoCales. 7. LAS MATERIAS CORRESPONDIENTES A LAS DISTINTAS ACTIVIDADES DE CONSECUCIÓN DE LOS INTERESES PÚBLICOS.

\section{LA PROBLEMATICA GENERAL DE LAS FUENTES DEL DERECHO LOCAL}

\section{El dualismo ratio-auctoritas en la teoría de las fuentes DEL RÉGIMEN LOCAL}

La teoría general de las fuentes, sobre todo cuando se la va a contemplar desde la perspectiva de las que corresponden al Régimen Local, no puede exponerse sin recordar previamente, aunque sea de modo sumario, algunas de sus claves evolutivas, en la medida en que están incidiendo, todavía intensamente, sobre el presente. Como casi todos los productos de la cultura jurídica europea, la teoría de las fuentes del Derecho forma parte del legado que la Baja Edad Media, transformando fundamentalmente materiales romanos y canónicos, transmite a la Edad Moderna. Se trata de ese ius commune que recibe la Europa renacentista y en cuyo seno hay formuladas, desde el principio, una serie de reglas de derecho que luego se recogen y se transforman, desde la perspectiva de sus fundamentos, por el sistema jurídico del iusnaturalismo racionalista. Ese conjunto de reglas expresan esencialmente una ratio. Frente a las mismas surgen y se consolidan unos Derechos nacionales en cada uno de los territorios en que se va constituyendo el Estado "moderno", que vienen a ser la plasmación de una voluntas, de la auctoritas de la realeza. Ese dualismo entre ratio y auctoritas trasciende a la teoría social y política llegando a expresarse plásticamente en la contraposición entre el Derecho natural, que desde la segunda mitad del siglo XVIII se convierte en arma arrojadiza, frente a los distintos Derechos positivos que ha ido creando el Estado absolutista. En el fondo, la exigencia de una ratio a la norma equivalía a que albergara una solución justa, en cuanto el Derecho ha de ser expresión de lo justo, un punto de vista sobre la justicia. Pero, claro, el Derecho ha de contar también con auctoritas, ha de ser manifestación de una voluntad que puede, que está legitimada porque el propio Derecho se lo permite, proporcionar a sus mandatos el valor de normas jurídicas. 
Desde el punto de vista de las fuentes del Derecho positivo, el dualismo auctoritas-ratio se plantea, pues, durante largo tiempo, en una situación de escisión pura y simple: constituyen Derecho los mandatos del soberano, porque es el único que puede investir a su voluntad de la indispensable auctoritas; frente al mismo se invoca otro Derecho, el Natural, que carece de aquélla pero que debe valer porque es expresión misma de la ratio. Después, la teoría de la Ley que engendra el positivismo las coordina, en la medida en que entiende que el Parlamento es portador de la voluntad de la Nación - la única que puede crear normas jurídicas-, y esa voluntad, la voluntad general en la concepción de RouSSEAU, lleva siempre consigo la ratio. Al margen de cuanto se perciba después de exageración, lo cierto es que, entonces, la Ley es la única fuente del Derecho. Como fuentes residuales, sin embargo, hubo que reconocer la costumbre y los principios jurídicos generales. Se trataba, con este reconocimiento, de atender a los vacíos u omisiones que presentara la Ley. En uno y otro caso, además, sin la virtualidad organizatoria reconocida a ésta, la costumbre sería la puramente local («del lugar», señalaba el Código Civil) y los principios habrían de formularse mediante un proceso de inducción de las reglas más generales, a partir de las concretas y singulares formuladas por el legislador. En realidad, pues, la única auctoritas posible quedaba en manos del legislador estatal; era él quien, en todo caso, investía a la costumbre y principios generales - al remitirse a ellas en cuanto fuentes subsidiarias- de la fuerza bastante para convertirse en normas integrantes del Derecho positivo. Esta es la situación, en materia de fuentes, dominada por el principio de estatalidad del Derecho, que se sustenta sobre estas dos afirmaciones sustanciales: $1 .^{\circ}$ ) el Derecho positivo tiene exclusivamente su origen en el Estado y se produce solamente a través de los órganos del mismo: la voluntad del Parlamento vale como Ley, y en un plano de subordinación, el Gobierno podrá promulgar Reglamentos para la adecuada ejecución de aquélla; $2^{\circ}$ ) sólo la Ley, y por derivación el Reglamento, constituyen fuente del Derecho positivo, y es ella la que en ocasiones excepcionales proporciona vigor a la costumbre y los principios generales.

Paulatinamente, el esquema clásico queda afectado por crisis sucesivas que operan su transformación hasta situar el tema de las fuentes en sus términos actuales. En esencia, son las siguientes: $1 .^{\circ}$ ) crisis de la Ley en cuanto portadora, siempre y en todo caso de ratio y auctoritas. En la segunda postguerra mundial, sobre todo tras el análisis de la experiencia nacional-socialista, queda al descubierto que la Ley puede carecer de ratio y no ser, por ello, Derecho; $2^{\circ}$ ) transformación de las 
concepciones sobre el Estado: del Estado como organización externa a la Sociedad, como simple aparato de poder, al Estado-comunidad, como estructura en la que se integran y participan los grupos sociales; y, consiguientemente, del Estado centralizado a la descentralización, en la que adquieren la condición de sujetos las diversas colectividades, sobre todo las territoriales, que constituyen la Nación. La consecuencia, para la teoría de las fuentes, es el reconocimiento de que la auctoritas necesaria a las normas no es ya monopolio de los órganos estatales: también los órganos de las colectividades jurídicamente organizadas contarán con la capacidad necesaria para producir sus propias reglas de derecho. Frente a la concepción del ordenamiento jurídico del Estado como único se pasa a la de una pluralidad de ordenamientos que guardan entre sí las necesarias relaciones de inordinación; $3 .^{\circ}$ ) en la concepción clásica, la Sociedad sólo puede crear Derecho mediante la costumbre, y ésta vale porque y sólo cuando los órganos estatales le han proporcionado la necesaria auctoritas. La evolución pone de relieve la necesidad de reconocer a la Sociedad, en su actuación directa y no a través de los órganos de las entidades en que se integra, una participación más activa en el sistema de producción del Derecho Y, desde luego, la costumbre se sostiene -el Derecho Local proporciona demostraciones frecuentes- porque es la propia sociedad civil la que, al margen de los poderes constituidos, proporciona una característica auctoritas a determinadas reglas de conducta sostenidas a lo largo del tiempo: en su práctica y respeto por todos reside esa auctoritas; $4 .^{\circ}$ ) Es también la propia sociedad civil la que proporciona su auctoritas a los principios jurídicos generales. Estos constituyen, sobre todo, una expresión mediante una característica configuración técnica que los transforma en reglas de derecho- de creencias sociales arraigadas. La Sociedad, haciendo suya la ratio inherente a los principios, y acatándolos, los pone en vigor, les proporciona una peculiar auctoritas. Ayudan, desde luego, a la tarea de elaboración, de construcción en forma de reglas de derecho, los órganos depositarios de la función aplicativa del Derecho, en sus diversas manifestaciones.

Los trazos que se acaban de señalar, aunque no puedan ser ahora objeto de examen, constituyen el marco de entendimiento de los problemas de las fuentes del Derecho Local. En primer lugar, la auctoritas que sostiene las reglas de derecho se distribuye entre una pluralidad de titulares de poderes de creación jurídica: el Estado, las Comunidades Autónomas y cada Entidad Local. Pero, además, las propias colectividades locales, actuando por sí mismas y no a través de los órganos que las representan, asumen una peculiar posición en el sistema de fuentes 
del Derecho Local, llegando a alterar incluso, en algún aspecto, la rígida concepción jerárquica que sitúa, siempre y en todo caso, a la costumbre por debajo de las normas elaboradas y aprobadas por los órganos de la Entidad. Además, la vigencia efectiva de ordenaciones determinadas, una vez que el legislador constituido le retira su apoyo formal, acaba reposando sobre la auctoritas que las propias sociedades locales les prestan. No se trata tan sólo de situaciones hace tiempo englobadas en el marco de un Derecho Local Común y pese a él. En el seno de este último, incluso, la lógica inmanente al mecanismo de derogación de las normas anteriores por las posteriores que se le opongan queda, a veces, neutralizada por la continuidad con la que colectividades determinadas siguen acomodando su conducta a un Derecho que, con arreglo a aquella lógica, es ya pura historia. Así, por ejemplo, ha ocurrido y ocurre con pequeñas colectividades que han seguido organizadas con arreglo a la Ley Municipal de 1877, cuando desde el Estatuto de 1925 el régimen de Juntas Administrativas había quedado sustituido por el de Entidad Local Menor; o la pervivencia de estas Entidades en el núcleo capitalidad del Municipio, pese a la ulterior prohibición de la Ley; o las Comunidades de Villa y Tierra, que creía extinguidas una Real Orden de 1852. Fenómenos éstos, y otros análogos, imponen una consideración más pragmática y menos dogmática del papel que la sociedad civil asume en el sistema de fuentes del Derecho Local.

La segunda consideración a realizar deriva del hecho mismo de la existencia de una pluralidad de ordenamientos jurídicos, frente a la anteriormente postulada unicidad del ordenamiento estatal. No tiene aquí cabida, sin embargo, un examen de la problemática de esa pluralidad, sino tan sólo la que se plantea desde la perspectiva de la fuentes, y más concretamente las del Derecho Local. Y esto exige contemplar, aunque sea en pura panorámica, la posición que el Derecho Local ocupa en el Derecho Administrativo. De ella se desprenden unas relaciones de integración del propio Derecho Local, de imprescindible examen en las fuentes para este último. Relaciones que dependen, además, de la solución previa a un problema hasta ahora planteado de manera harto convencional: el del propio contenido del Derecho Local, en el seno del Derecho Administrativo Común. Y eso, aun aceptando, también convencionalmente, que aquél constituya tan sólo una parte del Derecho Administrativo. 


\section{FUENTES AUTÓNOMAS Y HETERÓNOMAS}

Ahora la ordenación de las fuentes ha de tomar como punto de partida la idea de pluralidad de origen, de poderes normativos diversos que se mueven en ámbitos de ordenación diferentes, no siempre conectados entre sí por un vínculo estrictamente jerárquico, aunque característicamente entrelazados, que dan vida a una pluralidad de ordenamientos jurídicos; uno de ellos, el ordenamiento de las Entidades Locales.

La configuración del ordenamiento local no es, claro está, fruto exclusivo de las Entidades Locales. El conjunto de reglas y principios por el que éstas se rigen, el Derecho propio de cada una de las colectividades locales, es fruto del esfuerzo creador de sus propios órganos y de los de las colectividades territoriales en los que están insertas. Se distinguen, así, fuentes autónomas y heterónomas en el Derecho Local. Las primeras descansan sobre los poderes de creación del Derecho reconocidos por la Constitución y la legalidad ordinaria a los órganos de la colectividad (Reglamento orgánico, Ordenanzas) y a la propia colectividad (costumbres locales). Las segundas, sobre los poderes normativos otorgados a los órganos del Estado y la correspondiente Comunidad Autónoma. La calificación para cada fuente, de autónoma o heterónoma, tiene un doble significado: técnico y político. Técnicamente, es heterónomo todo poder y toda norma producidos fuera de la Comunidad en la que es aplicable. Pero en el plano de la política legislativa la cuestión no es tan simple. Por una parte, cada colectividad local se integra en otras de nivel superior (Estado, Comunidad Autónoma) y, por consiguiente, una parte de su Derecho propio constituirá el efecto primordial de formar parte de esa colectividad superior: no será, en este sentido, heterónomo porque su propia población es también parte de esa colectividad superior. Lo que constituyan intereses generales de ésta habrá de quedar cubierto por las reglas de derecho que la misma promulgue. Hay, pues, un Derecho propio de las Entidades Locales que habrá de ser común a todas ellas o a todas las de cada Comunidad Autónoma. El problema, en el plano de la política legislativa, estriba en medir y calibrar el alcance de lo que ha de ser común a fin de no reducir en demasía lo que también en el plano estrictamente político se reconozca como marco para el autogobierno local y la creación propia de reglas de derecho. Singular trascendencia tiene también el dato de que los titulares de los poderes normativos locales no queden colocados en situación de dependencia jerárquica, sino que en el campo que se les otorgue como propio puedan adoptar las decisiones normativas con plena eficacia, sin el añadido de controles de autoridades superiores. 


\section{LA CONCURRENCIA DE PODERES NORMATIVOS: LA PLURALIDAD DE SITUACIONES DESDE EL PUNTO DE VISTA DE LA ORDENACIÓN DE LAS FUENTES}

Tomando, pues, como punto de partida la concurrencia sobre el Régimen Local de una pluralidad de poderes normativos, hay que examinar ahora las relaciones de posición que guardan entre sí; relaciones que no responden, desde luego, a un único y simple vínculo de jerarquía como se vino afirmando bajo el principio de estatalización de las fuentes. Tampoco las reglas de derecho que estos poderes producen se relacionan entre sí, siempre y en todo caso con arreglo al principio de jerarquía. Existen, en efecto, varias situaciones diferentes a constatar, según la intensidad y carácter de la relación entre los poderes normativos y las normas que dictan.

Un primer grupo de situaciones responde a una característica común: el sistema de producción de normas ha contemplado el ámbito a regular escindido en compartimientos estancos; en cada uno de ellos queda legitimado para actuar el correspondiente poder normativo, el que ocupa el entorno asignado sin atender a mandatos o instrucciones del legislador superior. Su competencia no está, pues, vinculada a declaraciones de voluntad normativas procedentes de otros sujetos. EI bloque de la legalidad responde aquí a la idea de fraccionamiento en estratos, y en el interior de cada uno los poderes legitimados para ello crean reglas de derecho en condiciones de mutua independencia incondicionadamente, en el ejercicio de su propia autonomía. Ahora bien, cada uno de los estratos normativos así creados guarda una relación con los demás, relación que puede configurarse con arreglo a varias alternativas. En unos casos responde a la situación de supremacía de los poderes territoriales de nivel superior. Entonces, el Derecho creado por las Comunidades Autónomas ha de observar el principio de no contradicción de las normas emanadas del Estado, y el de cada Entidad Local no podrá contradecir el de la Comunidad Autónoma en que se integra ni el del Estado. La hipótesis hasta ahora más analizada, dentro de este supuesto, es la correspondiente al binomio legislación estatal básica-legislación autonómica de desarrollo.

Las normas producidas en cada compartimiento no se conexionan, pues, entre sí con arreglo a la idea de jerarquía, sino de pura y simple inordinación: las del ente territorial inferior no pueden oponerse a las que promulgue el superior, actuando tan sólo una de las tradicionales consecuencias de la jerarquía, la de no contradicción de la norma superior por parte de la inferior. La indispensable coherencia del ordenamiento queda tan sólo pendiente de la efectividad de esta regla nega- 
tiva. En todo caso, porque a cada voluntad normativa le quedan, en su nivel, soluciones optativas entres las que escoger frente a cada problema que se presente. Ahora bien, el funcionamiento correcto de esta hipótesis gravita sobre una precisión que ha de contener el sistema de producción de normas: la de los límites que no pueden traspasarse en los niveles superiores de normación, porque las interpretaciones extensivas de la propia competencia van siempre en detrimento de la competencia del inferior: una interpretación amplia de lo básico en materia de Régimen Local por parte del Estado lleva inexorablemente consigo una disminución del campo que se abandona a la legislación autonómica de desarrollo y, en último término, a la potestad local de ordenanza.

Un segundo supuesto a contemplar dentro de este primer grupo de situaciones es aquel en que la relación entre estratos y poderes no es de prevalencia a favor del superior sino de suplencia, por éste, de los vacíos que se presenten en los estratos normativos inferiores. El sistema de producción normativa ha legitimado a cada poder para que se desenvuelva en el ámbito de la propia competencia. Pero permite la entrada de un poder, el superior, en el entorno reservado a otro, si el titular se inhibe o no agota el propio campo de regulación. La relación entre poderes y normas es, entonces, de supletoriedad. Existe supletoriedad, y no subsidiariedad, porque esta invasión del campo ajeno sólo se producirá cuando el ordenamiento que presenta una laguna - el autonómico o el de una Entidad Local- no ha logrado cubrirla recurriendo agotadoramente a sus propias fuentes, incluidas las subsidiarias (costumbre y principios generales), y se ha de aplicar, entonces, una norma ajena. Cumple, así, el Derecho del Estado una de sus funciones primordiales, la de asegurar, siempre y en todo caso, la existencia de una regla de derecho capaz de resolver el problema planteado. Como se verá después, es ésta una situación que se produce en el Derecho Local, aplicándose Derecho estatal no básico en bastantes de sus aspectos, en tanto no promulguen el suyo las Comunidades Autónomas.

La Disposición Transitoria Primera de la LRBRL determina que el Texto Refundido que el Gobierno promulgue -y lo hizo en el Real Decreto legislativo 781/1986, de 18 de abril-incorporará preceptos de carácter no básico que "constituyen la legislación del Estado transitoriamente aplicable», en tanto no promulguen las Comunidades Autónomas la que les corresponde. Pero no debe estimarse esta hipótesis como transitoria: podrá también existir cuando una Comunidad Autónoma estime que las soluciones del Derecho estatal le son idóneas, inhibiéndose entonces y no promulgando una regulación propia y distinta para ese problema. 
Existe, en fin, un tercer supuesto a contemplar: aquél en que los poderes y sus normas no están situados en una conexión propia de la verticalidad. La fractura en estratos no lleva consigo la afirmación del principio de no contradicción de la norma superior, sino su contrario: la habilitación expresa para que el poder normativo inferior pueda establecer sus propias reglas, aunque contradigan las previsiones normativas establecidas por el legislador o legisladores superiores. Estas últimas dejan de aplicarse si los titulares de poderes normativos inferiores utilizan la posibilidad jurídica de crear una propia normativa; colocándose, en tal caso, la del superior como Derecho supletorio. Es lo que ocurre, en la LRBRL, con el Reglamento orgánico que puede promulgar para si cada Corporación local; el mero hecho de aprobarlo relegará el Derecho estatal no básico y el de la Comunidad Autónoma, en las materias afectadas, a la función integrativa o de suplencia en último grado.

En el segundo grupo de supuestos, el sistema de producción normativa prevé una vinculación más intensa entre los poderes normativos, llamados a la construcción conjunta de un bloque de legalidad relativo a materia o conjunto de problemas determinados. El poder de cada uno cumple la función de cubrir su estrato normativo desenvolviendo los principios y reglas sentadas en el superior, de suerte que, además del principio de no contradicción, juega también el de consecuencia: entre las normas de cada estrato hay una coherencia interna de modo que los inferiores son fruto del desenvolvimiento del anterior y conjunto de consecuencias extraídas del mismo. Son de notar, aquí también, algunas variedades. La más conocida es aquella en que el vínculo jerárquico actúa con toda intensidad entre los distintos poderes normativos. Es el caso de la conexión, ampliamente estudiada, entre Ley y Reglamento. El poder reglamentario en el Reglamento ejecutivo sólo tiene sentido frente a la Ley, para hacer nacer las normas que constituyan el complemento indispensable para la plena aplicación de la misma. Pero, junto a esta hipótesis extrema, se colocan otras en que el vínculo de superioridad de un legislador sobre otro, o de las normas de cada uno, se afloja y desaparecen algunos de sus efectos. La construcción conjunta de algunos ordenamientos sectoriales, por ejemplo, se realiza reservando al Estado la legislación básica y a las Comunidades Autónomas la de desarrollo, pero este desarrollo no es libre, sino que queda vinculado por el sentido y la orientación proporcionados por el legislador estatal. Esta segunda modalidad de legislación de desarrollo ha sido detectada y puesta de relieve por el Tribunal Constitucional. No se trata de ceñirla al estricto alcance y carácter de complemento indispensable, 
como en el caso anterior, pero tampoco, como en la otra concepción del desarrollo normativo, se puede considerar la legislación estatal como un límite, algo que no se puede contradecir: entre la legislación estatal y el desarrollo legislativo a cargo de las Comunidades Autónomas existe, además de la no contradicción, una coherencia interna: ésta es, en definitiva, un conjunto de consecuencias extraídas de aquélla. Hay, en fin, una tercera hipótesis a contemplar: aquella en que la coherencia interna entre la norma subordinada y la superior viene, además, apoyada en instrucciones o mandatos que el legislador superior consigna - por ejemplo, en una delegación o encomienda normativa para vincular al inferior-. Los tres supuestos se observan, desde luego, en la creación del Derecho Local.

\section{DeRecho local y Derecho administrativo Común}

El examen de las fuentes del Régimen Local exige también tener presente esta distinción, pues determinados aspectos de su regulación quedan incardinados en el marco normativo general para las Administraciones Públicas, desgajándose otros, por el contrario, a fin de proporcionar a aquéllas soluciones propias y distintas. En este punto, y atendiendo ahora tan sólo a los criterios generales, se observa una evolución legislativa que ha ido decantando un Derecho Administrativo común a todas las Administraciones Públicas. Es el que las contempla en sus rasgos generales: organización y marco jurídico de relaciones con otros sujetos (estructura y medios, procedimiento, actos y contratos, responsabilidad...) y en su despliegue en los distintos sectores de actividad pública asignando competencias concretas a las distintas Administraciones portadoras de los intereses generales que cubre cada ordenamiento sectorial. El Derecho Local se extiende más allá de esas reglas comunes, ciñéndose a contemplar la problemática especifica de su constitución, posición jurídica, organización y funcionamiento. Sienta también algunas reglas concretas, relativas a la presencia de las Entidades Locales en los distintos ordenamientos sectoriales.

Desde la perspectiva global, el ordenamiento administrativo puede, pues, desintegrarse en ordenamientos propios de los sujetos y ordenamientos sectoriales o de actividad. En el primero de estos apartados se distingue, a su vez, un estrato común a todos ellos, o todos los de un territorio, y otro compuesto por las reglas propias de cada clase o categoría e, incluso, de entidades concretas. El Derecho Local corresponde, desde luego, a esta segunda especie, como un Derecho propio de las 
Entidades Locales que se sitúa más allá del Derecho Común a todas las Administraciones Públicas. Desde la perspectiva de las fuentes, esto plantea el ya clásico problema de las relaciones entre Derecho Común y Derecho especial. Y por otra parte, las que se entablan entre Derecho general, aplicable a la totalidad del territorio, y Derechos territoriales particulares (forales y especiales).

Hasta aquí la situación del Derecho Local, en el contexto del Derecho Administrativo. Lo que permitirá analizar las relaciones de posición que ha de guardar el mismo con otros bloques normativos. Pero, a su vez, en el interior del propio Derecho Local, se hace imprescindible separar y distinguir lo que es común a todas las Entidades, o a todas las de un mismo territorio, y lo que es peculiar de algunas o alguna. Junto al Derecho común a todas las Administraciones Públicas queda el que es común a todas las Administraciones Locales, o todas las de la misma clase o territorio. A continuación, el Derecho propio de cada una. En principio es a los órganos del Estado y de la correspondiente Comunidad Autónoma a quien corresponde la promulgación del Derecho Local común, y a cada Entidad lo que se conciba como reglas peculiares de ella. Y ello, tanto en materia de organización (ordenamientos subjetivos) como de actividad (ordenamientos sectoriales).

Las distinciones que quedan apuntadas generan un complejo sistema de relaciones que ha de plantearse teniendo en cuenta tanto el carácter de los poderes normativos que cada ente ejerce como el ámbito de competencia que le ha sido otorgado. Relaciones que, ante todo, se tensan ante dos característicos problemas: el de colisión entre reglas procedentes de poderes distintos, y el de vacío o laguna en la normación encomendada a cada poder concreto. En el pasado estos problemas - partiendo de los principios de unicidad y estatalidad del ordenamiento- se resolverían atendiendo al principio de jerarquía de las normas y a la técnica de la subsidiariedad; este último como secuela del anterior, ya que las normas subsidiarias son fruto de fuentes colocadas en escalones inferiores de la propia jerarquía de fuentes. Excepcionalmente se entablaba una conexión con ordenamientos externos recurriendo a la técnica de la supletoriedad, que lleva consigo la incorporación para el caso de una norma procedente de otro sistema de fuentes. El Derecho Común - tanto el Administrativo o general como el Local- desempeña, pues, tres funciones en el sistema de fuentes: $1 .^{a}$ ) como la primera de las fuentes a que se ha de atender, en cuanto contiene el "común denominador normativo", como el estrato normativo de general e incondicionada aplicación; $2{ }^{a}$ ) como Derecho subsidiariamente aplicable, en defecto de normas procedentes de la Comu- 
nidad Autónoma correspondiente o incluso de la propia Entidad Local, en aquellos ámbitos objeto de configuración normativa conjunta entre dos o más poderes normativos territoriales, por concurrir diversos tipos de intereses públicos no claramente aislables y diferenciables; $3 .^{a}$ ) como Derecho supletorio, tanto de Derechos territoriales que responden a otros principios de configuración (los Forales) como de ámbitos de ordenación regidos por el principio de autonomía (con su propio sistema de fuentes), cuando carezcan de recursos de ordenación propios.

\section{EL PLANTEAMIENTO ANALITICO DE LA LEGALIDAD: LA DISTINCION DE AMBITOS DE REGULACION Y LA PLURALIDAD DE TITULOS COMPETENCIALES EN CONTRASTE}

El planteamiento actual de la distribución de las competencias normativas sobre el Régimen Local es fruto de un proceso interpretativo, aun no concluido, que se inicia a partir de los preceptos de la Constitución de 1978, que se refieren al Régimen Local, tomando después como punto de apoyo los Estatutos de Autonomía y la legislación ordinaria, singularmente la propia LRBRL. A lo largo de este proceso se van clarificando las competencias normativas que ostentan el Estado y las Comunidades Autónomas sobre el Régimen Local, que era de lo que se trataba. Pero, en realidad, también se va desentrañando el propio significado de esta trama institucional. Como consecuencia última, la imposible consideración unitaria del mismo en el sistema de fuentes: se va dando vida a un tratamiento analítico, dividiéndolo en ámbitos de regulación, en cada uno de los cuales se hace imprescindible el contraste entre los distintos títulos competenciales atribuidos al Estado, las Comunidades Autónomas y cada Entidad Local.

1. LA CONSIDERACIÓN DEL RÉGIMEN LOCAL DESDE LA PERSPECTIVA DE SUS FUENTES EN LA CONSTITUCIÓN Y EN LA LRBRL

A) El proceso interpretativo de los preceptos constitucionales: la clarificación de la competencia normativa del Estado.

a) El artículo 149.1.18 de la Constitución como fundamento de la distribución: sus límites

La distribución de competencias en materia de fuentes del Régimen Local dista de ser, por el momento, una cuestión definitivamente clari- 
ficada. No obstante, es el propio proceso de clarificación el que de modo más decisivo está contribuyendo a dibujar la concepción del Régimen Local - bien entendiéndolo como conjunto de instituciones, bien como Derecho propio de las mismas-que realmente alberga la Constitución y debe ser objeto de desarrollo por el legislador ordinario. Por de pronto, está claro que el Régimen Local no constituye una de las «materias" a que se refieren los artículos 148 y 149 de la Constitución, a efectos de reparto de competencias entre el Estado y las Comunidades Autónomas. Así, desde luego, ha podido llegar a entenderse si se atendía a una primera pauta interpretativa que adolece, no obstante, de una excesiva simplicidad: la de identificar toda la problemática de regulación del Régimen Local con la que es propia de las Administraciones Públicas o de una determinada especie de las mismas. Esta interpretación toma como punto de apoyo la rúbrica del Capítulo II del Título VIII de la Constitución - "de la Administración Local»- y sitúa, en consecuencia, el criterio de distribución de las competencias normativas en el artículo 149.1.18, que asigna al Estado las bases del régimen jurídico de las Administraciones Públicas y del régimen estatutario de los funcionarios públicos. Tomando este último precepto como punto de apoyo se realiza un reparto de competencias sobre el Régimen Local en los Estatutos de Autonomía de Cataluña, País Vasco, Andalucía, Valencia y Ley de Amejoramiento del Fuero de Navarra. Así, el Estatuto de Cataluña señala en su artículo 9.8 lo siguiente: "La Generalidad de Cataluña tiene competencia exclusiva sobre las siguientes materias ... 8 Régimen Local, sin perjuicio de lo que dispone el número $18 \mathrm{del}$ apartado $10^{\circ}$ del artículo 149 de la Constitución. Alteraciones de los términos municipales y denominación oficial de los Municipios y topónimos». El artículo 10.1 y 4 del Estatuto del País Vasco se plantea la cuestión, como resultaba indispensable, aludiendo a las competencias de los Territorios Históricos y de la propia Comunidad Autónoma, en relación con el Régimen Local; las competencias de los Territorios Históricos quedan reconocidas en el artículo 37 del Estatuto, en tanto que éste señala como competencia de la Comunidad Autónoma, con carácter exclusivo, la correspondiente al «Régimen Local y Estatuto de los funcionarios del País Vasco y de su Administración Local, sin perjuicio de lo establecido en el artículo 149.1.18.a de la Constitución». En términos semejantes, pero sin aludir a competencias sobre funcionarios locales, se pronuncian el Estatuto de Andalucía (art. 13.3) y el de Valencia (art. 31.8), que añade la competencia correspondiente a la denominación oficial de los Municipios y topónimos. La Ley de Amejoramiento de Navarra recoge las competencias ya reconocidas en la Ley Paccionada de 16 de agosto de 
1841 y las disposiciones que la siguen y complementan, más las que siendo compatibles con las anteriores, puedan corresponder a las Comunidades Autónomas o a las Provincias, conforme a la legislación básica del Estado.

La dinámica legislativa y la interpretación de la jurisprudencia constitucional iban a poner en seguida de relieve que este enfoque del reparto de competencias normativas se queda corto, sobre todo cuando se advierte que la problemática que el Régimen Local presenta para el Estado no queda ceñida a la cuestión del régimen básico de las Administraciones y su personal. Consiguientemente, tampoco la competencia exclusiva de algunas Comunidades Autónomas podía interpretarse como apoderamiento para normar todo aquello que no estuviese incluido, como competencia estatal, en el artículo 149.1.18.

Y es que el artículo 137 de la Constitución alberga un precepto que no puede ser entendido como pura retórica: la consideración de las Entidades Locales como elementos integrantes de la organización territorial del Estado no puede entenderse limitada a consecuencias puramente funcionales -en cuanto puntos de apoyo de la gestión, sobre cada territorio, de los fines de interés general-, sino que plantea un tema de concepción, de configuración del Régimen Local de acuerdo con el modelo de Estado que la propia Constitución ha dibujado. Es por ello obligado que el propio legislador estatal incida sobre las instituciones locales acomodando su estructura y funciones a los trazos subrayados por el constituyente en materia de organización del propio Estado. Se trata, pues, de una acción reflexiva sobre la propia organización. Así lo hace ya notar la Sentencia de 28 de junio de 1981, del Tribunal Constitucional:

«la garantia constitucional (de la autonomía local) es de carácter general y configura un modelo de Estado, y ello conduce, como consecuencia obligada, a entender que corresponde al mismo la fijación de los principios o criterios básicos en materia de organización y régimen de las Corporaciones Locales."

En el mismo sentido, refiriéndose ahora al tema de las competencias, la Sentencia de 5 de agosto de 1983 del mismo T. C. señala que

«las competencias de las Corporaciones Locales no pueden quedar a merced de la interpretación que ćada Comunidad Autónoma haga del derecho a la autonomía local, pues tal autonomía viene exigida por el modelo de Estado que la Constitución configura.»

La elaboración y promulgación de la Ley Orgánica del Régimen Electoral General constituye, a continuación, otro hito trascendente 
para desentrañar el haz de significaciones que confluyen en el Régimen Local y la necesaria consideración analítica de sus fuentes. El artículo 140 de la Constitución remite «in genere» a la ley la regulación de la dimensión representativa de las Corporaciones Locales. El legislador estatal y luego la jurisprudencia constitucional interpretan el pensamiento del constituyente en el sentido de que dicha dimensión ha de quedar contemplada en aquella Ley Orgánica. Se localiza así un ámbito de regulación diferente del contemplado en el artículo 149.1 .18 y, en el mismo, un título competencial en favor del Estado, sin perjuicio de la legalidad complementaria a cargo de las Comunidades Autónomas. A estas alturas, el proceso interpretativo había decantado en un doble resultado: no consistía tan sólo en el señalamiento de tres ámbitos de normación, sino además el significado global que el Régimen Local tiene en el Estado y en la Constitución. A partir de ahí la temática de las fuentes del Derecho Local se hace más compleja, por el juego cruzado de los diversos títulos competenciales de incidencia sobre esta realidad institucional.

b) El minimo contenido habilitante del artículo 148.1.2. de la Constitución

Salvo el Estatuto de Asturias, que consigna en favor de la Comunidad competencia para el "desarrollo legislativo» en materia de Régimen Local, los demás iban a tomar como punto de conexión fundamental el precepto incluido en el artículo 148.1.2. ${ }^{\circ}$ de la Constitución. Además, algunos de ellos contienen una declaración específica de competencia sobre instituciones típicas del propio territorio, estableciéndose una habilitación general y, por consiguiente, también de competencia normativa para la regulación de dichas instituciones. Así, el Estatuto de Galicia (art. 27.2) establece la competencia exclusiva de la Comunidad Autónoma para la «organización y régimen jurídico de las Comarcas y Parroquias rurales como entidades locales propias de Galician; el Estatuto de Asturias (art. 11.a) difiere esa específica competencia a la Comunidad para las "denominaciones de los Concejos comprendidos en su territorio, así como la creación de organizaciones de ámbito inferior y superior a los mismos», determinando en su artículo $6 .^{\circ}$ que "se reconocerá personalidad jurídica a la parroquia rural como forma tradicional de convivencia y asentamiento de la población asturiana». En último término, el Estatuto de Canarias recoge en su Disposición Transitoria Séptima una determinación de la mayor trascendencia, adoptada tácitamente por el Estatuto, cual es la liquidación de los organismos 
provinciales, las Mancomunidades Interinsulares, estableciendo el sistema de reparto de las competencias y medios de las mismas.

El problema que presentan desde el punto de vista de la competencia normativa de las Comunidades Autónomas este segundo grupo de Estatutos, como los restantes, es que - salvo el de Asturias- no incluyen una cláusula habilitante del desarrollo legislativo de la legalidad estatal básica en materia de Régimen Local. Aparte las concretas menciones que realizan a Entidades supra e inframunicipales, han tomado como punto de apoyo para la atribución el artículo $148.1 .2 .^{\circ}$ de la Constitución, según el cual las Comunidades Autónomas podrán asumir competencias en relación con

«las alteraciones de los términos municipales comprendidos en su territorio y, en general, las funciones que correspondan a la Administración del Estado sobre las Corporaciones Locales y cuya transferencia autorice la legislación sobre Régimen Local.»

En realidad este precepto no contempla habilitación de competencias legislativas, ya que con una interpretación extensiva la Administración del Estado sólo podría tener las de carácter reglamentario: la Ley de Régimen Local atribuiría, en todo caso, al Gobierno poderes puramente reglamentarios. Consiguientemente, estas Comunidades Autónomas no tienen, en principio, competencia para el «desarrollo legislativo" del Régimen Local: no pueden contar con una Ley de Régimen Local propia. Sus únicos títulos habilitantes están consignados en los propios Estatutos, pero se refieren a figuras concretas de Entidades supra e inframunicipales. A lo sumo, pueden incidir sobre el Régimen Local en su conjunto mediante la legislación de desarrollo del régimen jurídico de las Administraciones Públicas, a partir de la legalidad estatal básica, y en la ordenadora de su propia organización territorial. Uno y otro títulos competenciales, en realidad, suponen una incidencia incompleta, en un caso, e indirecta, en el otro. No hay, pues, para ellas la posibilidad de una propia Ley de Régimen Local; al menos mientras no amplíen su competencia estatutaria al amparo de lo que dispone el artículo 148.2 de la Constitución.

B) Los criterios de la LRBRL: homogeneización de la competencia comunitaria y construcción plural del orden de prelación de fuentes

La LRBRL recoge el proceso interpretativo decantado en parte, añadiendo a su vez precisiones e interpretaciones ya indispensables. En lo que toca al Régimen Local como parte integrante de la organización 
territorial del Estado y las Comunidades Autónomas, se plantea solamente el esquema de relaciones interadministrativas y los mecanismos esenciales de articulación entre el Estado y las Corporaciones Locales. No toca, en este tema, un problema de fuentes. Lo mismo ocurre en lo que atañe al sistema de representación, remitiéndose a lo que disponga "la legislación electoral general» (art. 19.1), y en la asignación de competencias administrativas, que se llevará a cabo por «la legislación del Estado y la de las Comunidades Autónomas reguladora de los distintos sectores de acción pública" (art. 2.1).

Acotada asi la materia -esto es, con un criterio prácticamente residual- la LRBRL se plantea dos problemas sustanciales en materia de fuentes. Primero, el de resolver sobre las competencias normativas de las Comunidades Autónomas que se habían remitido en sus Estatutos al artículo 148.1.2. ${ }^{\circ}$ de la Constitución; es decir, que solamente ejercerán sobre las Entidades Locales «las funciones que correspondan a la Administración del Estado sobre las Corporaciones Locales y cuya transferencia autorice la legislación sobre Régimen Local». Segundo, tras una disección analítica de los sectores de regulación establece el orden de prelación de fuentes correspondientes a cada uno (art. $5^{\circ}$ ). Las dos cuestiones presentan una profunda interrelación, y su clarificación llevaría consigo, ante todo, la delimitación de las competencias normativas de las Comunidades Autónomas que no se han atribuido competencia exclusiva sobre el Régimen Local en su conjunto.

Por lo que hace a la primera de estas dos cuestiones, la LRBRL incluye, en la Disposición Adicional Primera, el precepto siguiente:

«las competencias legislativas o de desarrollo de la legislación del Estado sobre Régimen Local asumidas, según lo dispuesto en sus respectivos Estatutos, por las Comunidades Autónomas del Principado de Asturias, Cantabria, La Rioja, Murcia, Aragón, Castilla-La Mancha, Castilla y León, Islas Baleares, Extremadura y Madrid, se ejercerán, según los casos, en el marco de lo establecido en el artículo 13 y en el Título IV de esta Ley, así como, si procediere, en los términos y con el alcance previstos en los artículos 20.2, 32.2, 29 y 30 de la misma."

Se realiza, pues, un encauzamiento de competencias normativas estatutarias hacia determinados aspectos del Régimen Local. Pero dándose por supuesto, al menos en apariencia, que tales competencias están efectivamente situadas en los correspondientes Estatutos. Lo que está claro en lo relativo a las alteraciones de la división del territorio en Municipios (art. 13); casi la misma claridad y generalidad en lo que se refiere al Título 10 (Entidades supra e inframunicipales); no lo está, en modo alguno, en la materia a que se refieren los restantes preceptos 
que se mencionan, esto es, órganos complementarios de Municipios y Provincias y regímenes municipales especiales. Las expresiones que la Disposición Adicional emplea ( $" . .$. en el marco de lo establecido en el artículo...») hacen suponer que el legislador estatal está haciendo uso de la facultad habilitante contenida en el artículo 150.1 de la Constitución, otorgando así, en estos aspectos, potestad legislativa a las Comunidades Autónomas que menciona. Pero en seguida se advierte que no: que la LRBRL parte de que en los Estatutos que menciona existe una atribución de competencias normativas sobre el Régimen Local ("según lo dispuesto en sus respectivos Estatutos») y lo que pretende es limitarla reconduciéndola a sólo determinados aspectos del mismo. En realidad, ni tal competencia normativa existe en esos Estatutos ni la LRBRL podría, si la hubiera, limitarla. Por otra parte, tampoco ella otorga competencia normativa ninguna a estas Comunidades, al pretender tan sólo recortar unas competencias normativas que todavía no existen en favor de estas Comunidades. Si se impone esa interpretación no formal se accede así a una homogeneización de la competencia normativa comunitaria en un aspecto sustancial del Régimen Local: el que atañe a su estructura y a la modulación del régimen municipal común en los convenientes regímenes especiales.

\section{AMBitos SUSTANCIALES DE REGULACIÓN EN EL RÉGIMEN LOCAL}

La consecuencia, tras este señalado proceso de interpretación y desarrollo legislativo, es la de que las fuentes del Régimen Local no pueden ser objeto de una consideración unitaria sino analítica. Y la misma ha de tomar como esquema tres ámbitos distintos de regulación: $\left.1^{\circ} .^{\circ}\right)$ el Régimen Local como conjunto de instituciones representativas; $2 .^{\circ}$ ) la concepción de las Entidades Locales como Administraciones Públicas; $\left.3 .^{\circ}\right)$ la cualidad jurídica que a las mismas se otorga como sujetos integrantes de la organización territorial del Estado y de las Comunidades Autónomas. Sobre cada uno de estos ámbitos el título competencial de que son portadores el Estado, las Comunidades Autónomas y las propias Entidades Locales encuentra su contenido habilitante en contraste con otros títulos competenciales que pudieran provocar una incidencia normativa sobre el aspecto correspondiente del Régimen Local.

La LRBRL, no obstante, al recoger y sistematizar las fuentes del Derecho Local, no ha contemplado en toda su complitud estas tres dimensiones del Régimen Local. En lo que atañe a la representativa se remite, desde luego, a la "legislación electoral general» (art. 19.1), desig- 
nando, en lo que ésta no deja cubierto, las competencias normativas que han de abarcar los demás aspectos. Tampoco aborda frontalmente la problemática del Régimen Local en cuanto parte integrante de la organización territorial del Estado y las Comunidades Autónomas, aunque sí se refiere a la ordenación del esquema de relaciones interadministrativas y los mecanismos esenciales de articulación entre los entes territoriales. Se centra, en cambio, en la consideración de las Entidades Locales como Administraciones Públicas. En el mismo avanza sobre el planteamiento analítico de la problemática de las fuentes. El precepto fundamental se contiene en el artículo $5 .^{\circ}$, que distingue los distintos sectores de regulación y el orden de prelación de fuentes en los términos siguientes:

«Las Entidades Locales se rigen, en primer término, por la presente Ley, y además:

A) En cuanto a su régimen organizativo y de funcionamiento de sus órganos: por las Leyes de las Comunidades Autónomas sobre Régimen Local y por el Reglamento orgánico propio de cada Entidad en los términos previstos en esta Ley.

B) En cuanto al régimen sustantivo de las funciones y los servicios:

a) Por la legislación del Estado y la de las Comunidades Autónomas, según la distribución constitucional de competencias.

b) Por las Ordenanzas de cada Entidad.

C) En cuanto al régimen estatutario de sus funcionarios, procedimiento administrativo, contratos, concesiones y demás formas de prestación de los servicios públicos, expropiación y responsabilidad patrimonial:

a) Por la legislación del Estado y, en su caso, la de las Comunidades Autónomas, en los términos del artículo 149.1.18 de la Constitución.

b) Por las Ordenanzas de cada Entidad.

D) En cuanto al régimen de sus bienes:

a) Por la legislación básica del Estado que desarrolle el artículo 132 de la Constitución.

b) Por la legislación de las Comunidades Autónomas.

c) Por las Ordenanzas propias de cada Entidad:

E) En cuanto a las Haciendas Locales:

a) Por la legislación general tributaria del Estado y la reguladora de las Haciendas de las Entidades Locales, de las que será supletoria la Ley General Presupuestaria.

b) Por las Leyes de las Comunidades Autónomas en el marco y de conformidad con la legislación a que se refiere el apartado anterior.

c) Por las Ordenanzas Fiscales que dicte la correspondiente Entidad Local, de acuerdo con lo previsto en esta Ley y en las Leyes mencionadas en los apartados $a$ ) y $b$ ).” 


\section{EL ORDEN DE PRELACION DE FUENTES EN LOS DISTINTOS AMBITOS NORMATIVOS}

La problemática de las fuentes debe ahora abordarse desde un punto de vista analítico, examinando uno a uno los distintos ámbitos de regulación que han quedado distinguidos. En ellos habrá de tenerse en cuenta no sólo la competencia estatal o estatutaria, sino también el orden de prelación entre las distintas fuentes formales, atendiendo así a la correlación que en cada ámbito haya de haber entre las normas especialmente destinadas al Régimen Local y las que con carácter común se proyecten sobre el mismo; es el caso de la normativa sobre bienes, personal, etc., en la que se puede presentar, por ejemplo, en concepto de norma de prevalente aplicación la especial sobre los bienes de las Entidades Locales frente a la general o común ordenadora de los bienes de las Administraciones Públicas.

\section{LAS ESTRUCTURAS LOCALES Y SUS ELEMENTOS.}

REGIMENES COMÚN, ESPECIAL Y FORAL

A) Contenido de este ámbito a efectos de distribución de las competencias normativas

El primero de los apartados que conviene distinguir es el que podría denominarse estructuras locales. La expresión se toma aquí proporcionándole un significado convencional, para hacerla abarcar las Entidades Locales como sujetos y los elementos que, según el legislador, las integran; es decir, territorio y población, dejando a un lado el elemento organización que tiene un tratamiento aparte en el contexto de las fuentes. Así delimitado el ámbito, en el mismo se han de incardinar las competencias normativas para crear y suprimir tipos o clases de Entidades y para crear, suprimir o modificar concretas Entidades con arreglo a aquéllos. Habrá que examinar también los poderes en relación con el régimen de los elementos territorio y población. En último término se ha de incluir aquí la competencia para otorgar a las Entidades existentes o que se creen el régimen local común, especial o foral.

\section{B) Competencia estatal y comunitaria}

La Constitución, en punto a tipología de las Entidades Locales se refiere, según se expresó ya, a los Municipios, Provincias e Islas, aña- 
diendo una cláusula en cuya virtud el legislador ordinario puede incrementarla siempre que se trate de agrupaciones de Municipios distintos de la Provincia. La legislación estatal básica completa la norma constitucional diseñando el elenco de Entidades Locales. No cabe pensar en una competencia comunitaria de creación de tipos nuevos, aunque la LRBRL es lo bastante flexible como para que tengan cabida las modulaciones regionales precisas, a partir de los niveles de convivencia recogidos por el legislador estatal como base para las estructuras locales.

En el marco de la clasificación de Entidades así establecida hay que situar ahora las competencias para establecer la consiguiente ordenación jurídica. En este sentido al Estado se atribuye la promulgación del nivel básico general, pero el mismo lo ocupa con muy diversa amplitud: en lo que concierne a las Entidades previstas en la Constitución, el "común denominador normativo" se extiende al tratamiento de todos los problemas que las mismas pueden plantear, aunque dicho tratamiento sea esquemático y permita el ulterior desarrollo comunitario. Las demás Entidades quedan situadas bajo la competencia normativa de las Comunidades Autónomas a partir, simplemente, del trazo definitorio elemental que contiene la LRBRL. Del mismo modo, por consiguiente, y atribuyendo a Municipios y Provincias la condición de tipos de Entidades Locales comunes a todo el territorio estatal (con el añadido de las Islas en los Archipiélagos), la creación de otros tipos adicionales de Entidadés, así como de regímenes municipales especiales, es materia propia de las Comunidades Autónomas (las supra e inframunicipales). A recordar, no obstante, el supuesto foral propio del País Vasco, cuyo Estatuto atribuye (art. 37.3) a los Territorios Históricos todo lo relativo a "demarcaciones territoriales de ámbito supramunicipal que no excedan de los límites provinciales». Precisamente en este y otros supuestos la creación histórica - largo tiempo mantenida como norma en muchos aspectos consuetudinaria - tiene un papel harto significativo. Añade el artículo 30 LRBRL que "las leyes sobre Régimen Local de las Comunidades Autónomas, en el marco de lo establecido en esta Ley, podrán establecer regímenes especiales para Municipios pequeños o de carácter rural y para aquellos que reúnan otras características que lo hagan aconsejable como su carácter histórico-artístico o el predominio en su término de actividades turísticas, industriales, mineras u otras semejantes». Es de observar, a este respecto, que este artículo 30 remite a la potestad normativa estatutaria la regulación, en materia de regímenes municipales especiales, a partir de los preceptos de nivel básico; consiguientemente, pueden construir, en condiciones de identidad de 
ámbito competencial, estos regímenes especiales apartando a los Municipios de su territorio, cuando reúnan las características señaladas de toda la normativa que no tenga carácter básico y aun en el caso en que la correspondiente Comunidad no tenga, en materia de Régimen Local, otras competencias que las que la propia LRBRL le transfiere. En último término y todavía en materia de estructuras locales, se ha de recordar lo dispuesto en los artículos 42 a 45 inclusive de la LRBRL, que defiere a las Comunidades Autónomas el establecimiento de entidades intermedias entre Municipio y Provincia e inferiores a aquél. Concretamente, la Ley tipifica las Comarcas y las Areas Metropolitanas, así como las "Entidades de ámbito territorial inferior al Municipio».

Si de la creación y régimen de la tipología se pasa ahora a su aplicación a la realidad -creación, modificación y supresión de Entidades - encontramos en el punto de partida el dato de que la Constitución ha reservado a las propias Cortes Generales, mediante Ley orgánica, "cualquier alteración de los limites provinciales" (artículo 141.2). En cambio, habilita el otorgamiento a las Comunidades Autónomas de los poderes precisos para las "alteraciones de los términos municipales comprendidos en su territorio" (art. 148.1.2. ${ }^{\circ}$ ). Consiguientemente, la estructura provincial queda reservada, en lo que atañe a su alteración, a la competencia normativa estatal, proyectándose, en cambio, sobre la municipal la de las Comunidades Autónomas. A tales efectos, el artículo 13 de la LRBRL establece que "la creación o supresión de Municipios, así como la alteración de términos municipales se regulará por la legislación de las Comunidades Autónomas sobre Régimen Local», añadiendo algunos trámites preceptivos a incluir en los correspondientes procedimientos administrativos. Se establecen igualmente en el precepto los requisitos sustanciales que han de estar presentes en la creación de nuevos Municipios. El Estado se reserva, por su parte, el establecimiento de medidas que tiendan al fomento de la fusión de Municipios a fin de mejorar la capacidad de gestión de los asuntos públicos locales.

La cita textual de la LRBRL permite contrastar el problema de habilitación normativa que queda latente tras el enfoque proporcionado al problema por la Disposición Adicional Primera de la misma. En todos los preceptos que se acaban de citar el legislador remite la normación de desarrollo a las Leyes de Régimen Local que promulguen las Comunidades Autónomas. Siempre, por supuesto - según lo señalado por su Disposición Adicional Primera- en base a la habilitación con que cuentan en sus propios Estatutos de Autonomía. Por tanto, en principio, y salvo que prevalezca la interpretación finalista de 
dicha Disposición Adicional, sólo las Comunidades Autónomas con competencia exclusiva de desarrollo legislativo en materia de Régimen Local, o de regulación concreta de determinadas Entidades, podrán hacer uso de todas o algunas de las señaladas competencias de creación, regulación y establecimiento de las mismas.

Estamos en el terreno que, con cierta convencionalidad, hemos denominado "estructuras locales». Hay que plantearse, finalmente, si en el mismo tendrían también cabida los denominados elementos de las mismas; esto es, territorio, población y organización, a los que pueda añadirse el nombre y la capitalidad. Desde luego, la temática de la organización tiene su planteamiento específico, al que se aludirá después. Lo relativo a la población de las Entidades Locales refleja la presencia de varios títulos competenciales, tanto en la perspectiva global -la población como conjunto- como en la individual de vínculo que une a la persona con la Entidad. El dato de que la población es, al mismo tiempo, elemento de las diversas Entidades territoriales genera un título competencial específico en favor de cada una de ellas; el vínculo personal genera igualmente efectos en los diversos ordenamientos territoriales que se superponen. Desde la primera de estas dos perspectivas, la Constitución acota, como competencia exclusiva del Estado, la "estadística para fines estatales» (art. 149.1.13). La cobertura de estos fines se instrumenta en la actualidad a través de la actividad municipal de empadronamiento y elaboración de la propia cifra de habitantes, lo que provoca la consiguiente intervención de la Administración estatal en la gestión municipal. Intervención cifrada en la competencia normativa y determinados poderes de dirección, coordinación y control. Por otra parte, la vecindad administrativa constituye presupuesto para la atribución de cualidades jurídicas de relevancia en el Estado y las Comunidades Autónomas. Señaladamente, el censo electoral se elabora, en parte, teniendo en cuenta las inscripciones padronales (art. 35 de la LOREG), lo que fundamenta la intervención estatal en el entorno propio del correspondiente título competencial.

Los artículos 15 a 17 inclusive de la LRBRL constituyen la consecuencia de estos títulos, considerándose básica la clasificación de la población municipal y atribuyendo al Estado la legislación sobre formación, mantenimiento, renovación y rectificación del Padrón municipal de habitantes. Por otra parte, en el mismo se dejará constancia de «los datos personales precisos para las relaciones jurídicas públicas, con inclusión de los que el Estado o las Comunidades Autónomas soliciten a los Ayuntamientos en el ejercicio de las funciones de coordinación que a aquél o a éstas correspondan». 
La competencia estatal incluye la función normativa y, además, las de dirección y control. El RPDT señala al efecto que "las normas procedentes para la renovación» se aprueban por Real Decreto a propuesta conjunta de los Ministerios de Economía y Hacienda y Administración Territorial (ahora, Administraciones Públicas). Pero, además, habilita a la Administración del Estado para el ejercicio de una función de dirección cuando establece que el Instituto Nacional de Estadística y la Dirección General de Administración Local «dictarán, conjuntamente, las instrucciones y directrices de carácter técnico" necesarias (art. 67). Se trata, pues, de una actividad administrativa en la que se residencian en la Administración del Estado los poderes de ordenación, lato sensu, quedando circunscrita a la pura gestión la competencia municipal. Para la efectividad última de esos poderes están las facultades ulteriores del Instituto Nacional de Estadística, que prestará su conformidad a la renovación padronal o formulará "los reparos pertinentes" (art. 76). Ahora bien, tales conformidad o reparos se circunscriben a lo que es propio de los intereses generales: no tal o cual inscripción concreta, sino "las cifras de población de cada Municipio».

No obstante, cuando la renovación padronal coincida con la formación del Censo de población, el artículo 78 del RPDT contiene habilitaciones más amplias para la Administración del Estado, ya que «se coordinarán los trabajos relativos a ambas inscripciones, al objeto de racionalizar la realización conjunta de ambas operaciones». Los objetivos de normalización y economía de medios se hacen, en tal caso, más palpablemente presentes.

La temática del territorio como elemento de las Entidades Locales está planteada en la LRBRL, sobre todo desde el punto de vista de las alteraciones del mismo y, siguiendo una cierta tradición, dejando involucrada una cuestión más amplia, la de la constitución, modificación y extinción de las propias Entidades Locales. Hay, desde luego, otra perspectiva de tratamiento, que es la relativa al territorio como objeto de diversas titularidades y ámbito de ejercicio de competencias administrativas. En este sentido, la LRBRL no proporciona un criterio quedando, en principio, éste como un campo propio para las Comunidades Autónomas, siempre que tengan competencia exclusiva o de desarrollo legislativo en el Régimen Local. En las demás, será de aplicación directa el TRDLRL y el RPDT. Las alteraciones territoriales de los Municipios entran sin excepciones en la competencia legislativa de las Comunidades, al recoger sus Estatutos, al menos, la cláusula habilitante contenida en el artículo $148: 1.2^{\circ}$ de la Constitución. No así las 
alteraciones de territorios provinciales, que la Constitución asigna a las Cortes Generales y exige Ley orgánica.

Ahora bien, la alteración territorial no cabe en este esquema de ordenación cuando la línea límite que se pretende mover asume la calidad, además, de delimitadora del territorio de dos Comunidades Autónomas. O la supresión de un enclave municipal o provincial lleva consigo una alteración territorial a nivel de Comunidades Autónomas. La tesis que sienta el Tribunal Constitucional en Sentencia 99/86, de 11 de julio, toma como punto de apoyo la existencia constitucional de Ley orgánica - habrá siempre alteración de territorios provinciales y puede ser también exigible la misma cuando suponga modificación de algún Estatuto de Autonomía- a la que podrán preceder trámites establecidos en cada Estatuto de Autonomía; trámites que se sucederán si la previsión estatutaria se extiende tanto a la fase de segregación de una porción territorial propia como a la de agregación de ella al territorio de la otra Comunidad Autónoma. En todo caso, la cualidad predominante en el territorio -elemento integrante de una Comunidad Autónoma - sitúa la cuestión fuera del Régimen Local, en el ordenamiento territorial inmediatamente superior.

El nombre de los Municipios presenta una característica inflexión en las Comunidades Autónomas que presentan peculiaridad idiomática o variantes dialectales. En favor de la competencia de las mismas existen previsiones específicas en sus Estatutos. La competencia concreta se incluye también en la correspondiente al desarrollo legislativo del Régimen Local, como ocurre con la normación de la capitalidad. Frente a la competencia comunitaria, el TR y el RPDT quedan como Derecho subsidiariamente aplicable.

\section{La ORDENACIÓN DE LAS CORPORACIONES LOCALES COMO INSTITUCIONES REPRESENTATIVAS}

El contenido y alcance de este título competencial empieza a clarificarse a partir de la jurisprudencia que el Tribunal Constitucional va sentando en las Sentencias de 18 de diciembre de 1981, 16 de mayo de 1983 y 14 de julio de 1984. Es esta última la que precisa la materia en los términos siguientes:

"Para que una Ley merezca el calificativo de electoral es necesario que contenga por lo menos el núcleo central de la normativa atinente al proceso electoral, materia en la que se comprende lo relativo a quienes pueden elegir, a quien se puede elegir y bajo qué condiciones, para qué 
espacio de tiempo y bajo qué criterios organizativos desde el punto de vista procedimental y territorial.»

Por su parte, la Sentencia de 16 de mayo de 1983 examina y contrasta este título competencial con el que se deriva, en algunos Estatutos de Autonomía, de la cláusula de apoderamiento, en cuanto competencia exclusiva sobre el Régimen Local. Examina un recurso previo de inconstitucionalidad promovido contra el texto definitivo del proyecto de Ley Orgánica por la que se modifican determinados artículos de la Ley de Elecciones Locales, de 17 de julio de 1978. La Sentencia declara, a este respecto, lo siguiente:

"Para los recurrentes la expresión "régimen electoral general" que utiliza el artículo 81.1 de la Constitución española para acotar, con otros objetos, la materia reservada a la Ley Orgánica, comprende tan sólo el régimen jurídico de las elecciones para designar a los parlamentarios que han de componer el Congreso y el Senado, de modo que, así entendido, la indicada expresión es la Ley que ha de desarrollar lo previsto en los artículos 67 a 70 de la Constitución la que tendrá el carácter de orgánica, mas no la que en el marco constitucional del artículo 140 regule lo que es básico o fundamental en las elecciones locales. Sin embargo, esto no es asi porque si bien -en un primer análisis- la expresión "régimen electoral general" puede suscitar la duda, por eso se despeja, si la interpretación se la hace arrancar de los artículos 140, 68.1 y 23.1 de la Constitución. Y es que el artículo 140 (al igual que el artículo 68.1) reserva a la Ley el régimen de las elecciones locales en los aspectos que dice, Ley que por la misma exigencia del artículo 23.1 y la precisión que hace el artículo 81.1 entendiéndola la acción con los artículos 68.1 y 140, ha de ser una Ley Orgánica. Se reservará así a la Ley - a la Ley Orgánica- el régimen electoral general, tanto en las elecciones que tienen en los artículos 67 al 70 sus lineas constitucionales como de las elecciones que las tienen en el artículo 140. El contenido de la Ley Orgánica no se ciñe así al solo desarrollo del artículo 23.1, sino que es más amplio comprendiendo lo que es primario y nuclear en el régimen electoral; pues el artículo 81 ha comprendido la reserva de la Ley Orgánica, el régimen electoral general y, por lo tanto, no siendo nunca permisible entender ambas expresiones como una sola."

La Ley Orgánica 5/1985, de 19 de junio, del Régimen Electoral General, se refiere al sistema de representación de las Corporaciones Locales en sus Títulos III, IV y V. Su Disposición Adicional Primera-4 señala que el contenido de estos Títulos «no pueden ser modificados o sustituidos por la legislación de las Comunidades Autónomas». Ahora, en su consecuencia, el artículo 73.1 de la LRBRL establece que:

«... la determinación del número de miembros de las Corporaciones Locales, el procedimiento para su elección, la duración de su mandato y 
los supuestos de inelegibilidad e incompatibilidad se regularán en la legislación electoral.»

Es de observar, además, que el contenido de los tres mencionados Títulos de esta Ley Orgánica se califica como "Disposiciones especialesi para las elecciones municipales, de Cabildos Insulares Canarios y Diputaciones Provinciales. Normas de Derecho especial que, a su vez, se integran en una simbiosis peculiar con el Derecho electoral general, recogido en los restantes títulos de aquella Ley, en el que se contienen los principios configuradores de este bloque de legalidad y las reglas que pudieran llegar a ser objeto de aplicación subsidiaria.

Es a partir de estas normas especiales y generales donde se encuentra el campo de normación propio de las Comunidades Autónomas. La LOREG no contiene, por otra parte, una habilitación expresa en favor de ellas, sino que se remite a lo que disponga el Estatuto de cada una (Disposición Adicional Primera-1). Por consiguiente, podrán contar con una legislación propia, siempre y cuando cuenten con la competencia bastante en materia de Régimen Local (exclusiva o de desarrollo legislativo). El problema es aquí el mismo que en el anterior apartado: sólo las Comunidades Autónomas que cuenten con competencia normativa sobre Régimen Local, en la medida en que se la otorgue su Estatuto, podrán abordar el desarrollo legislativo de este ámbito de regulación. Legislación que a partir de los principios y normas que siente la legislación estatal podrá tener extensión muy diferente: bastante limitada, en relación con Municipios, Provincias e Islas, y amplia en lo referente a composición, procedimiento de selección, duración del mandato y supuestos de inelegibilidad e incompatibilidad, de las restantes Entidades Locales, pues sólo aquellas tres se contemplan directamente en la LOREG. En lo que atañe a estas últimas, el Derecho comunitario asumirá la consideración de norma especial (es, en realidad, una prolongación de las de la misma naturaleza contenidas en los Títulos III, IV y V de la LOREG) cuando se promulgue. «En su defecto", el artículo 199 prevé las normas de aplicación a las Entidades de ámbito territorial inferior al Municipio. Y es que en éstas se da también un fenómeno de representación directa de la colectividad, en tanto que en las que surgen de la agrupación de Municipios son ellos los que van a integrar los órganos representativos de la Entidad. Así lo establece de modo expreso -obviando las hipótesis de participación vecinal directa- la LRBRL en sus artículos 42 y 43.

Resta añadir la particularidad del Derecho Foral en este punto. El artículo 37.3 del Estatuto del País Vasco sitúa en los Territorios Histó- 
ricos la competencia sobre «organización, régimen y funcionamiento de sus propias instituciones», "demarcaciones territoriales de ámbito supramunicipal" y "régimen electoral municipal».

Junto a los temas de la determinación del número de miembros, procedimiento electoral, duración del mandato y causas de inelegibilidad e incompatibilidad, queda el del estatuto de los miembros de las Corporaciones Locales, respecto del cual los artículos 63 a 78 inclusive de la LRBRL sientan la normativa básica. A partir de ella, las Comunidades Autónomas con competencia exclusiva o de desarrollo legislativo en materia de Régimen Local pueden abordar la normativa correspondiente en el marco de esa característica dualidad de significados que contiene la expresión "desarrollo legislativo». En las demás Comunidades Autónomas será el Estado el que tenga la competencia normativa necesaria para agotar la materia mediante la correspondiente regulación.

La situación jurídica de los miembros de las Corporaciones ha sido también contemplada por TRDLRL y el ROF (título I). Ambos Cuerpos legales han de quedar, sin embargo, como Derecho estatal supletorio frente al que promulguen las Comunidades Autónomas. Ahora bien, es claro que también tendrá, en la dinámica real de dicha situación, una influencia directa el Reglamento orgánico de cada Corporación, que primará, desde luego, sobre cualesquiera otras normas que no tengan la condición de básicas en el ámbito que le asigna como propio la LRBRL.

3. El RÉGIMEN JURÍdico de las EnTidades Locales EN CUANTO AdMinISTRACIONES PÚBLICAS

\section{A) Contenido de este ámbito normativo}

El más amplio de los títulos competenciales que contempla la Constitución para verificar el reparto de la competencia normativa entre el Estado y las Comunidades Autónomas es el que incluye el artículo 149.1.18, cuando señala que el Estado tiene competencia exclusiva para establecer

«... las bases del régimen juridico de las Administraciones públicas y del régimen estatutario de sus funcionarios que, en todo caso, garantizarán a los administrados un tratamiento común ante ella; el procedimiento administrativo común, sin perjuicio de las especialidades derivadas de la organización propia de las Comunidades Autónomas; legislación sobre 
expropiación forzosa; legislación básica sobre contratos y concesiones administrativas y el sistema de responsabilidad de todas las Administraciones públicas.»

La determinación del alcance de la expresión régimen jurídico va a ser objeto de atención por el Tribunal Constitucional en diversas Sentencias. Así, la de 28 de julio de 1981 se resiste a identificar la expresión régimen jurídico con la totalidad del Derecho Administrativo: ni el uso de la expresión régimen jurídico para designar sólo el procedimiento y régimen de recursos en nuestra práctica legislativa es un criterio constante ni uniforme para todas las Administraciones Públicas que permita inducir de él la voluntad inequívoca del constituyente; ni, aunque lo fuera, podría aceptarse sin más esta interpretación sin apoyarla en otras razones que deriven directamente de la propia estructura constitucional. Tampoco puede afirmarse, sin más, que la expresión régimen jurídico de las Administraciones Públicas abarque en puridad todo el Derecho Administrativo, cuya clave es la sumisión de la Administración al Derecho, por el evidente motivo de que tal razón es en sí misma pura tautología reduccionista que restringe el Derecho Administrativo a su clave e identifica a ésta con las bases del régimen jurídico de las Administraciones Públicas. Por su parte, la Sentencia de 5 de agosto de 1983 vuelve a referirse al tema en los términos siguientes:

«La expresión régimen jurídico ... no se refiere exclusivamente al procedimiento y al régimen de recursos, como ha señalado este T.C. en su Sentencia de 28 de julio de 1981, y ha de entenderse incluida en ella también la regulación básica de la organización de todas las Administraciones Públicas."

En la primera de las Sentencias citadas se recoge una referencia explícita a las Cortes como institución en la que ha de irse decidiendo ese contenido básico:

«Ciertamente no será siempre fácil la determinación de qué es lo que ha de entenderse por regulación de las condiciones básicas o establecimiento del régimen juridico, y parece imposible la definición precisa y apriorística de este concepto. Las Cortes han de establecer qué es lo que haya de entenderse por básico, y en caso necesario será este Tribunal el competente para decidirlo, en su calidad de intérprete supremo de la Constitución.»

Sin embargo, a partir de la de 28 de enero de 1982, se admite que la definición de lo básico puede también realizarse por el Gobierno, lo 
que explica que el TR, en su Disposición Final Séptima, otorgue carácter básico a determinados de sus artículos, extravasando la previa delimitación realizada por las Cortes en la propia LRBRL. Lo que, por lo que conlleva de corrección del criterio legislativo a renglón seguido de su plasmación, resulta difícilmente justificable, aun teniendo en cuenta la propia doctrina del TC en Sentencias como la de 28 de abril de 1983. La competencia estatal se centra, en fin, en el entorno de «las bases del régimen jurídico de las Administraciones Locales", dejando en este campo el margen necesario para «las especialidades derivadas de la organización propia de las Comunidades Autónomas», según establece el propio artículo 149.1.18. La propia Sentencia últimamente citada así lo aclara:

"La fijación de estas condiciones básicas no puede implicar en ningún caso el establecimiento de un régimen uniforme para todas las Entidades locales de todo el Estado, ya que la potestad normativa de las Comunidades Autónomas no es en estos supuestos de carácter reglamentario."

Un recto entendimiento del contenido de este título competencial ha de tomar como punto de partida todo cuanto se desprende del sentido y alcance que para las Entidades Locales significa el otorgamiento de la cualidad jurídica que sustancialmente las caracteriza - al menos si se atiende a las propias expresiones formales del constituyente y a las formulaciones del Tribunal Constitucional-; que es, precisamente, la de Administraciones Públicas. La expresión "régimen jurídico», al referirse de modo directo a esta cualidad subjetiva, ha de abarcar el ius proprium de estos sujetos en cuanto tales entidades administrativas. Ese ius proprium, en lo que atañe a las Entidades Locales comprende, si se tiene en cuenta la trayectoria histórica, la problemática relativa a la propia constitución como tales sujetos y la posición jurídica peculiar que en cuanto Administraciones Públicas se les otorga. Está, desde luego, dentro del régimen jurídico de estos sujetos el tratamiento de su constitución como personas jurídicas concretas, porque el Derecho Público no permite la existencia de entes locales más que para que se constituyan como Administraciones Públicas. Lo que supone la normación del supuesto de hecho (existencia de una colectividad asentada sobre un territorio, diferenciación de las circundantes, viabilidad de la misma) y el procedimiento para el otorgamiento de la personalidad. Con ella la organización que se ha de dar al ente y las reglas de funcionamiento interno, y en sus relaciones con terceros. A partir de ahí, el régimen jurídico de las Administraciones Locales incluye el diseño de la peculiar posición jurídica que el Derecho positivo les 
confiere: si asumen el calificativo de Administraciones Públicas territoriales ello comportará un característico haz de privilegios, potestades $y$ deberes, aminorados si se las califica como no territoriales. Con esta dotación elemental el ordenamiento les asigna o reconoce un haz elemental de funciones - las competencias concretas son cosa propia de los ordenamientos sectoriales-y las coloca en un peculiar sistema de relaciones, a trabarse entre los demás entes que integran la Administración Pública en su conjunto. Cuestiones todas ellas que, a su vez, son susceptibles de regulación a través de un doble estrato normativo: uno, el Derecho común a todas las Administraciones Públicas, y otro, de acuerdo con la calificación jurisprudencial, el Derecho específico o especial de las Administraciones Locales. Esta distinción permite aclarar el alcance de los títulos competenciales que han de ser tenidos aquí en cuenta.

Desde luego, las Comunidades Autónomas con competencia exclusiva o de desarrollo legislativo del Régimen Local cuentan con el título competencial preciso para la promulgación de ese Derecho especial destinado a las Administraciones Locales, y con virtualidad bastante para abarcar los aspectos no básicos del mismo. Precisamente en sus Estatutos han tomado como límite de su esfera competencial, en lo que atañe al Régimen Local, el ya examinado artículo 149.1.18 de la Constitución. Incluso pueden también abordar la creación de un Derecho común (a nivel de desarrollo legislativo) para las Administraciones públicas de la Comunidad y locales de su territorio, pues cuentan también con competencia normativa bastante si se suma el título competencial referente al desarrollo del régimen jurídico de la propia Administración comunitaria.

Por el contrario, las Comunidades Autónomas sin competencia para el desarrollo legislativo en relación con el Régimen Local no podrán, por ahora, crear el Derecho especial ni tampoco el común a todas las Administraciones incardinadas en su territorio y distintas de la Administración directa o indirecta del Estado. Ello porque, en este aspecto, sus Estatutos se reservan una potestad de desarrollo legislativo referida siempre, y en todo caso, a su propia Administración Pública; dentro de la cual no cabe incluir a las Administraciones Locales en cuanto tales, sino a lo sumo en un aspecto concreto de las mismas: el de constituir elementos integrantes de la organización territorial de la Comunidad Autónoma correspondiente. Aspecto, no obstante, que encuentra su fundamento en una cualidad jurídica distinta, añadida a la que las califica como Administraciones Locales; el régimen de aquella cualidad no permite, desde luego, entrar en la regulación de detalles relati- 
vos al régimen jurídico propio de las Entidades Locales sino solamente, en todo caso, al régimen a que han de atenerse cuando actúen como elementos incorporados a la organización administrativa territorial de la Comunidad.

\section{B) El planteamiento analítico de la $L R B R L$}

La LRBRL distingue, en el ámbito que puede otorgarse a este título competencial, tres sectores de regulación: $1^{\circ}$ ) régimen organizativo y de funcionamiento de los órganos de las Entidades Locales; $2^{\circ}$ ) dentro del anterior, separa lo relativo a los órganos complementarios que puedan crearse junto a los de gobierno o básicos; $3 .^{\circ}$ ) procedimientos y formas de actuación frente a terceros ("contratos, concesiones y demás formas de prestación de los servicios públicos, expropiación») y responsabilidad patrimonial.

En el primero de estos sectores se cumple el esquema legislación básica estatal-legislación comunitaria de desarrollo. Pero el artículo $5 .^{\circ}$-A de la LRBRL se refiere, en relación con esta última, a las "Leyes de las Comunidades Autónomas sobre Régimen Locabi. Esto es, en principio sólo existirá una normativa comunitaria en las Comunidades que tengan atribuida competencia expresa para ello en su propio Estatuto de Autonomía. En las demás, es decir, aquellas que aún no han accedido a una competencia, estatutariamente otorgada, sobre el Régimen Local es el propio Estado el que ha de asumir la potestad de promulgación de la normativa de desarrollo. Y es que en la actualidad estas Comunidades no tienen, en lo que concierne al desarrollo de las bases del régimen jurídico de las Administraciones Públicas, más competencia que la referida a sus propias entidades administrativas. Así, por ejemplo, el Estatuto de Cantabria incluye las correspondientes cláusulas habilitantes en los términos siguientes: por una parte, el artículo 22 otorga a la Comunidad competencia exclusiva para la «organización de sus instituciones de autogobierno", y el 35 señala que le corresponde "la creación y estructuración de su propia Administración Pública, dentro de los principios generales y normas básicas del Estado". Sólo, pues, en la medida en que las Entidades Locales se integran en la organización territorial de la Comunidad - según prevé el art. 37- podrían sus competencias normativas afectar a las Entidades Locales; pero no en su dimensión sustancial, sino tan sólo y en la medida en que asuman funciones comunitarias. Hay, por consiguiente, que recurrir a los títulos competenciales que a estas Comunidades proporciona la LRBRL, a las que se remite el propio Estatuto. Y en la 
misma se encuentra, en efecto, el otorgamiento de una potestad de desarrollo relativa a las Entidades supra e inframunicipales a partir de unas mínimas prescripciones básicas. En relación con las mismas podrá, desde luego, reconocerse a estas Comunidades capacidad normativa en materia de "régimen organizativo y de funcionamiento». La promulgación de la legalidad autonómica colocará el Derecho no básico - disposiciones del TRDLRL y ROF- como Derecho supletorio.

Ahora bien, tanto la ordenación autonómica como la estatal recaen ante el Reglamento orgánico aprobado por la propia Corporación. Esta es la interpretación a que llega la Resolución de 27 de enero de 1987, de la Dirección General de Administración Local, una vez que la promulgación del ROF planteó problemas sobre su carácter y ámbito de aplicación. Interpretación que no se desprende con claridad del artículo $5 .^{\circ}$ de la LRBRL, en lo que se refiere a la organización y funcionamiento de los órganos básicos, pero que cuenta a su favor con la directriz constitucional de autonomía local. Dicha primacía del Reglamento orgánico está, en cambio, plenamente establecida, precisamente como excepción dentro de la rúbrica analizada por la LRBRL, en lo que toca a la organización complementaria de la de los órganos de gobierno. Se establece en virtud del poder de organización que la propia Ley estatal reconoce a Municipios, Provincias e Islas y que coloca en posición de primacía sobre la legalidad comunitaria (arts. 20.2, 32.2 y 41.1). Las normas sobre organización complementaria, dictadas por estas Entidades Locales rompen, pues, la cadena jerárquica establecida con carácter general, engarzando de modo directo con la normativa estatal básica y desplazando a la condición de normas subsidiariamente aplicables las que promulguen las Comunidades Autónomas (cuando tengan potestad, en sus Estatutos, para el desarrollo legislativo en materia de Régimen Local); se trata éste de un ámbito en el que el Estado considera necesario el respeto al poder de organización que, como característica expresión de su autonomía, ha de reconocerse a las Corporaciones Locales. La jerarquía de fuentes queda, pues, alterada en este punto, de suerte que será cada Municipio, Provincia e Isla - no las demás Entidades Locales- quien tenga competencia normativa para el desarrollo de la LRBRL; las normas comunitarias, cuando puedan promulgarse, serán de aplicación subsidiaria. La cuestión reside, por otra parte, en la extensión que deba darse a la expresión "organización municipal complementaria» empleada por el legislador estatal en el artículo 22.3, y "órganos complementarios", referida a las Diputaciones en el 32.2. Ha de recordarse que nuestro Derecho Local ha empleado hasta ahora concepciones restringidas de 
la materia organizativa; gran parte de lo que ahora puede entenderse como "organización complementaria» quedaba sistemáticamente regulada en el Reglamento de Servicios, junto al de Organización, en la legislación antecedente; se situaba la temática de los órganos para la gestión sectorial como un problema más del planteamiento de la actividad, no la organización, administrativa. Si este enfoque se obvia en el futuro, como sería lógico, aún queda por indagar si el poder local de autoorganización se extiende a la creación, tanto de órganos como de organismos dotados de personalidad jurídica propia; en la actualidad, la distinción entre unos y otros resulta ser, en el plano de la estructura interna de cada Corporación, poco consistente, y la elección entre una y otra fórmula organizativa se realiza siempre en atención a argumentos de racionalidad y eficacia gestoras. No tendría sentido, por tanto, privar a las Corporaciones Locales de esa facultad de escoger entre una $u$ otra alternativa organizatoria -como sucedería si se impone una interpretación restrictiva de su potestad organizativa- al caer dentro de su autonomía sólo la creación de órganos (desconcentración) y no de organismos autónomos (descentralización funcional). La propia LRBRL proporciona, además, los límites precisos a este poder local cuando se proyecta sobre el propio territorio, pues escapa al mismo la descentralización territorial: son las Comunidades Autónomas quienes pueden crear «Entidades de ámbito territorial inferior al Municipio" (art. 45), y los Ayuntamientos sólo pueden establecer "órganos territoriales de gestión desconcentrada" (art. 24).

El tercero de los contenidos distinguidos en este ámbito normativo es el relativo al régimen de la actividad local (procedimiento, vinculaciones con terceros, responsabilidad). En el mismo, la LRBRL remite a "la legislación del Estado y, en su caso, la de las Comunidades Autónomas, en los términos del artículo 149.1 .18 de la Constituciónı. Por supuesto, para que éstas promulguen una normativa especial sobre estos puntos para las Entidades Locales, han de contar con competencia exclusiva o de desarrollo legislativo sobre el Régimen Local. De lo contrario, carecen de título habilitante, porque tampoco lo es el precepto estatutario que les otorga competencia para el desarrollo del régimen jurídico de su propia Administración Pública y de los entes que dependan de ésta. A lo sumo, cabría entender que este artículo 5.C de la LRBRL coloca, a efectos de trazado de un Derecho común de aplicación subsidiaria tras el Derecho especial (exclusivamente de los Entes locales) el que las Comunidades Autónomas promulguen para su propia Administración. De este modo, todas las Administraciones Públicas radicadas en cada territorio comunitario contarían con un 
estrato común, en cuanto al régimen jurídico de actuación. Semejante interpretación del precepto es, sin embargo, más forzada que su contraria: la de que en las Comunidades Autónomas sin competencia exclusiva o de desarrollo legislativo en materia de Régimen Local, el régimen jurídico de actuación de las Corporaciones Locales corre a cargo del Estado, tanto en el estrato común a las Administraciones Públicas (salvo las comunitarias) como al especialmente destinado al Régimen Local.

\section{El personal al SERVicio de las ENTIDADES Locales}

La materia funcionarial ha de entenderse, en el más amplio sentido posible hasta abarcar la burocracia en su conjunto. Esto es, todos aquellos que realizan prestaciones personales retribuidas en favor de las Entidades Locales, tanto si dichas prestaciones se fundamentan en un vínculo administrativo como laboral, y trabado con carácter temporal o permanente. Así la concibe el artículo 89 de la LRBRL cuando señala que «el personal al servicio de las Entidades Locales estará integrado por funcionarios de carrera, contratados en régimen de Derecho laboral y personal eventual que desempeña puestos de confianza o asesoramiento especial». Ha de añadirse la hipótesis de colaboración temporal mediante contrato administrativo, reiteradamente prohibida (ahora, por la Disposición Transitoria Octava de la LRBRL) y ciertos contratos de obra que suponen la realización de trabajos sin la incorporación del obligado a la organización burocrática, contemplados también por la legislación de funcionarios públicos. Así lo interpreta la Sentencia del Tribunal Constitucional de 5 de agosto de 1983, sobre la LOAPA, que declara:

«El artículo 149.1.18 de la Constitución reconoce al Estado competencia exclusiva para dictar las bases del Régimen Jurídico de las Administraciones Públicas y el Régimen estatutario de sus funcionarios. De ello deriva una doble competencia estatal en materia de función pública: primera, competencia para regular los aspectos básicos de la situación personal de los funcionarios públicos; es decir, de la denominada relación de servicios, contenido indiscutible del régimen estatutario, y segunda, competencia para regular los aspectos esenciales de la organización de la burocracia de las Administraciones Públicas, pues la expresión «Régimen Jurídico" contenida en el precepto constitucional no se refiere exclusivamente al procedimiento y el régimen de recursos ... y ha de entenderse incluida también en ella la regulación básica de la organización de todas las Administraciones Públicas.» 
Así entendido el ámbito de ordenación, sobre el mismo señala la Constitución en su artículo 149.1.18 la competencia del Estado para establecer las bases del régimen estatutario de los funcionarios públicos. Naturalmente, es este último título habilitante de mayor extensión, constituyendo una de sus manifestaciones específicas lo relativo al régimen básico de los funcionarios de las Administraciones Locales. El Estado, en ejercicio del mismo, ha puesto en vigor dos ordenaciones: una, de carácter general, que está contenida en la Ley de Medidas para la Reforma de la Función Pública, de 2 de agosto de 1984, y otra, circunscrita a la Función Pública local, contenida en la propia LRBRL, artículos 89 a 104 inclusive. A ambas se refiere esta última al establecer el orden de prelación de fuentes en la materia, colocándolas por encima de los restantes estratos normativos: «los funcionarios al servicio de la Administración Local se rigen, en lo no dispuesto por esta Ley, por la legislación del Estado...» (art. 92.1). El nivel normativo básico, en lo que concierne al personal local, queda, pues, integrado por una legalidad especial (la incluida en la LRBRL) y la general, contenida en la legislación estatal sobre funcionarios públicos que tenga asignado carácter básico. Ambas guardan entre sí la característica relación del Derecho especial y el general.

Más problemática se presenta la clarificación de las competencias normativas de las Comunidades Autónomas. Hay que partir, desde luego, de lo dispuesto en sus propios Estatutos de Autonomía, que recogen tres posiciones diferentes: $\left.1 .^{\circ}\right)$ con competencia exclusiva sobre los funcionarios de la Administración Local (País Vasco), artículo $10.4 ; 2 .^{\circ}$ ) con competencia para el "desarrollo legislativo y ejecución" en lo relativo a funcionarios de la Administración Local (Baleares, art. 11.3; Extremadura, art. $\left.8 .^{\circ} .10\right) ; 3 .^{\circ}$ ) con las competencias que en materia de Régimen Local le otorgue la Ley estatal y, lógicamente también, la legislación del Estado en materia de funcionarios públicos.

En lo que atañe al primero de estos supuestos, la jurisprudencia constitucional ha debido contrastar y delimitar el alcance que, en el ámbito funcionarial, tiene la competencia comunitaria exclusiva sobre el Régimen Local, en general, y sobre los funcionarios de la Administración Local, en particular. Son de citar, al respecto, las Sentencias de 25 de octubre de 1983, 8 de febrero de 1982, 5 de agosto de 1983 y $25 / 83$, entre otras, en las que se impone un respeto, por parte de las Comunidades Autónomas dotadas de competencia exclusiva, a las determinaciones básicas a cargo del Estado.

En cuanto al supuesto segundo, está claro que las Comunidades de Baleares y Extremadura cuentan con competencia para el desarrollo 
legislativo de la legislación estatal básica sobre el personal local. Ahora bien, el ejercicio de esa competencia se ha de realizar a base del poder normativo propio de las habilitaciones para el desarrollo vinculado positiva y negativamente. La especificidad de este artículo habilitante, consignado en el correspondiente Estatuto, resulta expresamente reconocida en la Sentencia del Tribunal Constitucional de 25 de octubre de 1983. En principio, las demás Comunidades Autónomas sólo podrán contar con un título habilitante si se lo confiere la LRBRL expresamente. Esta, en el ya citado artículo 92.1, se remite, en efecto, tras la legislación estatal básica, a la legislación «de las Comunidades Autónomas en los términos del artículo 149.1.18 de la Constitución». Lo que lleva consigo una interpretación extensiva de este último precepto, que otorga competencias a las Comunidades Autónomas para el desarrollo de la legislación estatal en materia de funcionarios públicos; competencia que, en principio, habría que entender ceñida al personal ligado a la Comunidad por formar parte de su Administración directa o indirecta. Una interpretación amplia de este título competencial, de suerte que incluya la normación de desarrollo de los funcionarios de las Administraciones Locales radicadas en su territorio no tiene mucha lógica, puesto que implica borrar unas diferencias - los tres supuestos antes señalados- que vienen establecidas por los propios Estatutos de Autonomía. Diferencias que algún sentido han de tener cuando así constan en ellos. Sin embargo, se ha sostenido también la opinión de que esa rúbrica genérica del artículo 92.1 de la LRBRL, al remitirse, sin más, y considerándola como legislación subsidiaria y no meramente supletoria, a «la de las Comunidades Autónomas, en los términos del artículo 149.1.18 de la Constitución» está en realidad habilitando a todas para la normación de desarrollo de la función pública local. Se llevaría a cabo, así, una «homogeneización»-es la expresión empleada - de las competencias estatutarias en esta materia. Pero, con ello, se corre el riesgo de aplicar una misma concepción al personal local y al de las Comunidades Autónomas, cuando las nece. sidades y posibilidades, asi como la morfología de una y otra burocracia, son distintas. Riesgo que, por otra parte, hace realidad el TR. En efecto, sus artículos 140.2, 142, 144, y 147.2 y 150.4 se remiten expresamente a la legislación de las Comunidades Autónomas en cuanto al régimen de situaciones, derechos, deberes y sanciones de los funcionarios locales. En realidad, las Comunidades Autónomas de este supuesto tercero carecen de competencia para regular la función pública local, incluso en la Ley 30/1984, de 2 de agosto, de Medidas para la Reforma de la Función Pública (el art. 11 sólo las habilita para 
regular los funcionarios propios); hasta ahora, además, las Leyes sobre la materia de estas Comunidades - las del supuesto tercero- no han contemplado la función pública local.

\section{EL RÉGIMEN DE LOS BIENES}

En lo que atañe a los bienes que constituyen el patrimonio de las Entidades Locales, el legislador estatal ha tomado como punto de partida lo que dispone el artículo 132.1 de la Constitución, según el cual:

«La Ley regulará el régimen jurídico de los bienes de dominio público y de los comunales, inspirándose en los principios de inalienabilidad, imprescriptibilidad e inembargabilidad, así como su desafectación.»

El precepto no viene a precisar otra cosa que el rango de la legalidad que ha de regular los bienes demaniales y los comunales. La interpretación que lleva a cabo la LRBRL, concretamente en su artículo $5 .^{\circ}$-D, consiste en que al Estado corresponde el establecimiento del régimen básico de los bienes de las Administraciones Locales. A su vez, este nivel normativo básico queda compuesto por dos clases de preceptos: los que pueden clasificarse como especiales, destinados expresamente a los bienes locales (arts. 79 a 83 de la LRBRL) y los que, con carácter general, promulgue el Estado para la ordenación - siempre a nivel básico- de los bienes de las Administraciones Públicas. Convendrá destacar que la LRBRL presenta, en este punto, un breve esquema con la clasificación de los bienes y las notas fundamentales de su régimen jurídico. Por cierto que se incluye en el mismo una grave desviación de la tradición jurídica y hasta del vigente texto constitucional al situar, sin más, a los bienes comunales como una especie de los de dominio público.

Por debajo del nivel básico se plantea aquí el mismo problema que en materia de funcionarios. El artículo $5 .^{\circ}-\mathrm{D}$ de la LRBRL se refiere, tras la normativa básica, a la «legislación de las Comunidades Autónormas». Lo que puede entenderse en dos sentidos: uno, primero, en el que se reiteraría la superposición de la normativa especial (sobre bienes locales) y general o común (sobre bienes de las Administraciones Públicas radicadas en cada territorio comunitario) promulgada por cada Comunidad Autónoma; y otro, en el que se produce, sin más, una remisión a la legalidad comunitaria sobre bienes de las Administraciones Públicas, borrando la peculiaridad de régimen de los correspondientes a las Entidades Locales. En realidad, hay que entender que las 
Comunidades Autónomas con competencia normativa en materia de Régimen Local podrán dictar la legislación especifica de desarrollo sobre el patrimonio de los Entes locales; e, incluso, señalar como de aplicación subsidiaria el Derecho de la Comunidad sobre bienes de las Administraciones Públicas. Alli donde esa competencia no exista, la normativa de desarrollo será la que el propio Estado promulgue. Y, a título meramente supletorio, cabría entender aplicable, en todos los casos, la legislación de las Comunidades Autónomas, dictada como ordenación general y de desarrollo en materia de bienes de sus propias Administraciones Públicas.

El reciente Reglamento estatal de Bienes de las Entidades Locales, de 13 de junio de 1986, precisa el orden de prelación de fuentes en los términos siguientes: a) legislación básica del Estado en materia de Régimen Local; b) legislación básica del Estado reguladora del régimen jurídico de los bienes de las Administraciones Públicas; $c$ ) legislación que en el ámbito de sus competencias dicten las Comunidades Autónomas; $d$ ) en defecto de la legislación a que se refieren los apartados anteriores, legislación estatal no básica en materia de Régimen Local y bienes públicos (art. 1. .2). El precepto permite ahora sostener, apoyado por la propia interpretación reglamentaria, que el artículo $5 .^{\circ}-D$ de la LRBRL no confiere a las Comunidades Autónomas título competencial ninguno, sino que recoge y se refiere a los que cada una tenga en sus Estatutos: la "legislación de las Comunidades Autónomas" (art. $5^{\circ}$ ) en este tema será la que promulgue "en el ámbito de sus competencias»; esto es, de acuerdo con la habilitación estatutaria con que cada una cuente.

Hay que añadir, aquí también, la peculiaridad del Derecho Foral. El ya citado artículo 37.3 del Estatuto del País Vasco remite a los Territorios Históricos la competencia. Como señala la Ley 27/1983, de 25 de noviembre, sobre "Relaciones entre las Instituciones Comunes y los Organos Forales de sus Territorios Históricos» del Parlamento Vasco, a dichos Territorios corresponde el urégimen de los bienes provinciales y municipales, tanto de dominio público como patrimoniales o de propios y comunales" (art. $7^{\circ} .7$ ). Esto es, el desarrollo normativo de la legislación básica del Estado. Más allá del Derecho Foral, la costumbre tiene un papel trascendente, al que luego se aludirá.

\section{El régimen de las Haciendas locales}

Al señalar las fuentes del Régimen Local en materia de Hacienda, el artículo $5 .^{\circ}$-E de la LRBRL toma como punto de partida la declara- 
ción contenida en el artículo 133 de la Constitución, que otorga exclusivamente al Estado la potestad originaria de establecer tributos, añadiendo que las Comunidades Autónomas sólo pueden acordar su imposición y exigencia de acuerdo con lo dispuesto en la propia Constitución y las Leyes. Precepto que encuentra su contrapartida en lo dispuesto por el propio constituyente en el artículo 142, del que resulta el deber estatal de dotar las Haciendas Locales con los medios necesarios para su sostenimiento. El desarrollo de estas normas constitucionales se lleva a cabo por el legislador ordinario, en lo que aquí concierne, mediante una interpretación extensiva de la presencia del Estado en el sector. El constituyente se limita, de una parte, a distinguir entre potestad originaria y derivada en una de las dimensiones de la Hacienda, la correspondiente al poder tributario. En términos estrictos, está simplemente aludiendo a la necesaria descentralización de ese poder, a llevar a cabo por el legislador ordinario. En el artículo 142 señala, por otra parte, un nivel o estándard de conducta que ha de seguirse, por el propio Estado, al atender a la dotación de las Haciendas Locales: esa dotación ha de ser suficiente. El legislador ordinario va más allá: impone, como añadido, la centralización de las competencias normativas en esta materia. Las Haciendas Locales se regirán

«... por la legislación general tributaria del Estado y la reguladora de las Haciendas de las Entidades Locales, de las que será supletoria la Ley General Presupuestaria."

No hay, pues, un acomodo de la regulación al binomio normativa básica-legislación de desarrollo. El Estado asume la competencia normativa en su totalidad, configurando el ordenamiento tributario en su conjunto. Más aún, es la propia legalidad estatal la que se erige, en realidad, en mecanismo habilitante de la comunitaria. Señala, a este respecto, el artículo 106.1 de la LRBRL que

"las Entidades Locales tendrán autonomía para establecer y exigir tributos de acuerdo con lo previsto en la legislación del Estado reguladora de las Haciendas Locales y en las Leyes que dicten las Comunidades Autónomas en los supuestos expresamente previstos en aquélla."

Además, el ordenamiento tributario responderá a un criterio de uniformidad. De ahí que, en el estricto ámbito tributario, se altera la habitual situación de subsidiariedad de la norma general frente a la especial: primero se aplica a las Haciendas Locales la legislación general tributaria del Estado, y luego la legislación especial que para ellas promulgue el Estado. Orden de prelación que, sin embargo, no se 
aplica a la materia presupuestaria, en la que queda delante la normativa especial de las Entidades Locales y luego, considerándola como supletoria, la Ley General Presupuestaria. Esta situación de supletoriedad de dicha Ley está indicando que, en lo que atañe al régimen presupuestario (con todo lo que el mismo conlleva), el Estado puede construir una normativa local que descienda, incluso, al detalle; prácticamente agotadora de la materia. De ahí que en posición exterior al ordenamiento local queda como recurso normativo de último grado el ordenamiento promulgado para el propio Estado, la Ley General Presupuestaria.

La legislación de las Comunidades Autónomas será de aplicación - según el citado art. $5^{\circ}$-E - «en el marco y de conformidad» con la legislación estatal que queda señalada. Quiere ello decir que el binomio legislación básica-legislación de desarrollo se atempera aquí a un planteamiento diferente del habitual, pudiendo considerarse la legislación de las Comunidades Autónomas como la de las Corporaciones Locales, como un conjunto de normas que se colocan, en relación con la legalidad estatal, en un plano de relación más profundo que el que, con carácter general, se establece entre la normativa básica y la de desarrollo. Al tema se ha referido la Sentencia. Constitucional de 8 de febrero de 1982, en los términos que más atrás quedaron señalados. Se trata, como se recordará, de un supuesto en que

"se intenta sujetar más estrechamente la competencia legislativa comunitaria al marco de la legislación básica del Estado.”

La norma comunitaria se coloca, como la local, en una situación de vinculación positiva con la estatal, de la que constituye prácticamente una concreción a los fines de su mejor ejecución: la discrecionalidad del poder comunitario resulta extraordinariamente atenuada, de suerte que existirá si asi lo ha previsto la norma estatal, y en la medida en que la haya previsto. Aparece aquí, como relación entre las normas estatal, por una parte, y comunitaria y local, por otra, un lazo auténticamente jerárquico, con todas las consecuencias que la jerarquia lleva en el sistema de fuentes. El sistema de fuentes, en lo que se refiere a la Hacienda Pública, es evidente que hay que entenderlo a partir del punto culminante, que es el estatal, desde el que se va configurando a través de escalones normativos sucesivos, correspondientes a las diversas entidades territoriales, pero dotado de una coherencia interna y, además, manteniendo un vínculo jerárquico, de subordinación, la legislación de desarrollo y la local en relación con la legalidad estatal. Aquí no existe la capacidad de innovación que es propia de la norma- 
tiva de desarrollo en otros campos, y la normativa financiera de las Comunidades Autónomas y Entidades Locales no queda amparada por la atribución de una competencia "exclusiva», porque dicha competencia no existe aquí: sólo se trata en los escalones normativos subordinados al estatal, de desenvolver las consecuencias inherentes a la norma estatal, aunque en ciertos casos permita el propio legislador estatal diversas alternativas sobre las que pueden pronunciarse el legislador comunitario y el local.

7. LAS MATERIAS CORRESPONDIENTES A LAS DISTINTAS ACTIVIDADES DE CON. SECUCIÓN DE LOS INTERESES PÚBLICOS

Según se advirtió ya, el legislador estatal ha establecido una remisión a la legalidad propia de cada materia, en cuanto fuente de atribución de competencia a las Entidades Locales. Dicha legalidad reguladora puede ser, a su vez, promulgada por el Estado o por las Comunidades Autónomas. Consiguientemente, y a partir de la mención a determinadas materias que realiza el legislador estatal en el artículo 25 de la Ley $7 / 85$, es la Ley estatal o comunitaria la fuente de atribución de competencias concretas en cada sector del ordenamiento. Habría que añadir, aunque se precisará después, que sola y exclusivamente la Ley, no el Reglamento, porque así lo dispone el artículo 25.3 de la Ley 7/85; y es aquí donde hay que mirar a la Constitución y a los mecanismos en los que se prevé una redistribución de competencias entre el Estado y las Comunidades Autónomas, para establecer el reparto de las fuentes de producción de la normativa aplicable a las diversas actividades locales. En último término, así lo expresa textualmente el artículo $5 .^{\circ}-\mathrm{D}$ de la Ley estatal básica, cuando señala que el régimen sustantivo de las funciones y los servicios locales se regirá "por la legislación del Estado y la de las Comunidades Autónomas, según la distribución constitucional de competencias", quedando, como fuente en último término, las propias Ordenanzas de cada entidad.

Los órganos estatales y comunitarios constituyen, pues, fuentes de producción del Derecho aplicable a determinados sectores de la realidad, cada uno dentro de su propia esfera de competencias, y sus reglas de derecho quedan en la mencionada relación jerárquica. Entre uno y otro van dibujando los correspondientes ordenamientos sectoriales en que se fracciona el sistema jurídico en su conjunto. Será conveniente precisar que estos ordenamientos sectoriales constituyen la 
cobertura de unos intereses públicos que son compartidos por el Estado y las Comunidades Autónomas. Uno y otras tienen conferidas las competencias convenientes para la defensa y consecución de esos intereses, en la medida en que tienen una incidencia sobre su propia esfera jurídica; entre ellas, la correpondiente competencia normativa. El Estado construye el marco jurídico general de desenvolvimiento de las actividades de los sujetos, marco que tiene aplicación en todo el territorio nacional. Cada Comunidad, a su vez, desarrolla ese estrato general, completándolo con las normas adecuadas al tipo de incidencia que la actividad tiene en su territorio, o la peculiaridad que presenta en el mismo.

Ahora bien, la imagen de los ordenamientos sectoriales es la que corresponde a una consideración vertical del ordenamiento estatal en su conjunto. La perspectiva puramente horizontal nos muestra que las normas que con este carácter promulgue cada Comunidad constituyen una parte de su Derecho propio; se integran en el ordenamiento comunitario. Precisamente, en el poder de modular el régimen general de las competencias estatales, en su incidencia sobre el territorio de la Comunidad, y en lo que atañe a su desarrollo y ejecución por ésta, estriba una de las más típicas manifestaciones de la autonomía de la Comunidad. De lo que se desprende que este tipo de normas comunitarias cuentan con una doble naturaleza y vinculación. Por una parte, constituyen elementos integrantes de los citados ordenamientos sectoriales que tienen proyección sobre la totalidad del territorio nacional; por otro lado, se incardinan en el ordenamiento de la Comunidad. La subsidiariedad del Derecho estatal es fruto, precisamente, de la doble funcionalidad correspondiente a la naturaleza de la norma comunitaria y a la estatal: en la medida en que una norma comunitaria no exista o presente lagunas, la norma estatal cubre ese vacío de modo directo e inmediato. Y ello, en primer lugar, porque, en definitiva, la legalidad sectorial está protegiendo unos intereses generales que si ciertamente se presentan compartidos por el Estado y la Comunidad, el interés de ésta sólo está sustantivado en la medida en que ella misma constituye y forma parte de la colectividad nacional.

Así, pues, la norma comunitaria sólo se promulga cuando sus órganos de gobierno han considerado necesario atender a la propia peculiaridad mediante la ya señalada modulación de la normativa estatal. Si esa necesidad no existe o no ha sido tenida en cuenta, ello significa que no es precisa una protección específica, distinta de la general, para los intereses comunitarios en el sector de que se trate. Las exigencias de normación propia no existen, los intereses propios de la Comunidad 
y los generales del Estado coinciden en el encuentro de una misma solución normativa. No existe, pues, la laguna iuris en el ordenamiento de la Comunidad, sino que ésta aplica la norma estatal considerándola como norma propia, otorgándola la función de regla comunitaria. La subsidiariedad propiamente dicha surge ante la laguna legis.

Promulgada una norma comunitaria, se observa en ella una regulación incompleta, un vacío en el diseño del régimen jurídico aplicable a la actividad de la Comunidad. En tal caso, es el marco jurídico general de desenvolvimiento creado por el Estado el que proporcionará la respuesta concreta mediante la simple aplicación de sus principios y directrices generales. 0 , más específicamente, la proporcionará la norma de desarrollo, también de origen estatal, generada precisamente para aplicarse alli donde una Comunidad carezca de competencias de desarrollo en el sector.

La aplicación subsidiaria del Derecho estatal, en este supuesto, no debe plantear problemas, en la medida en que en el mismo radican los principios configuradores del ordenamiento sectorial, configurándose la norma comunitaria como fruto de un poder normativo subordinado a tales principios. 